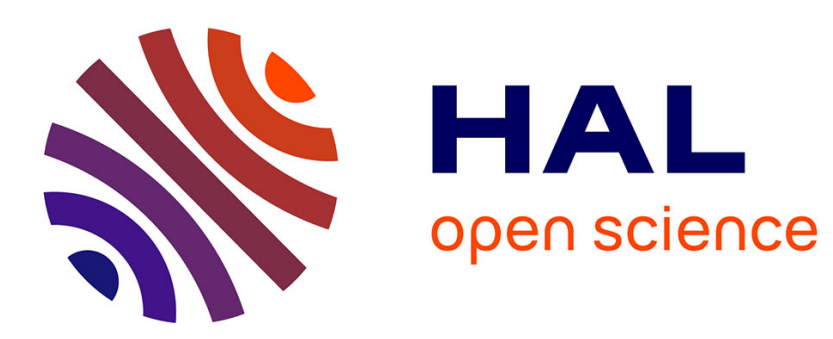

\title{
Pseudocapacitive oxide materials for high-rate electrochemical energy storage
}

Veronica Augustyn, Patrice Simon, Bruce Dunn

\section{To cite this version:}

Veronica Augustyn, Patrice Simon, Bruce Dunn. Pseudocapacitive oxide materials for high-rate electrochemical energy storage. Energy \& Environmental Science, 2014, vol. 7 ( $\mathrm{n}^{\circ}$ 5), pp. 1597-1614. 10.1039/c3ee44164d . hal-01171774

\section{HAL Id: hal-01171774 https://hal.science/hal-01171774}

Submitted on 6 Jul 2015

HAL is a multi-disciplinary open access archive for the deposit and dissemination of scientific research documents, whether they are published or not. The documents may come from teaching and research institutions in France or abroad, or from public or private research centers.
L'archive ouverte pluridisciplinaire HAL, est destinée au dépôt et à la diffusion de documents scientifiques de niveau recherche, publiés ou non, émanant des établissements d'enseignement et de recherche français ou étrangers, des laboratoires publics ou privés. 


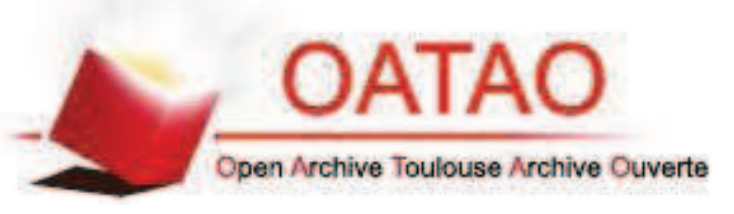

\section{Open Archive Toulouse Archive Ouverte (OATAO)}

OATAO is an open access repository that collects the work of Toulouse researchers and makes it freely available over the web where possible.

This is an author-deposited version published in: http://oatao.univ-toulouse.fr/ Eprints ID: 13900

To link to this article : DOI:10.1039/c3ee44164d

URL : http://dx.doi.org/10.1039/c3ee44164d

\section{To cite this version:}

Augustyn, Veronica and Simon, Patrice and Dunn, Bruce Pseudocapacitive oxide materials for high-rate electrochemical energy storage. (2014) Energy \& Environmental Science, vol. 7 ( ${ }^{\circ}$ 5). pp. 1597-1614. ISSN 1754-5692 


\title{
Pseudocapacitive oxide materials for high-rate electrochemical energy storage
}

\author{
Veronica Augustyn, $\uparrow^{\mathrm{a}}$ Patrice Simon ${ }^{\mathrm{bc}}$ and Bruce Dunn*a \\ Electrochemical energy storage technology is based on devices capable of exhibiting high energy density \\ (batteries) or high power density (electrochemical capacitors). There is a growing need, for current and \\ near-future applications, where both high energy and high power densities are required in the same \\ material. Pseudocapacitance, a faradaic process involving surface or near surface redox reactions, offers \\ a means of achieving high energy density at high charge-discharge rates. Here, we focus on the \\ pseudocapacitive properties of transition metal oxides. First, we introduce pseudocapacitance and \\ describe its electrochemical features. Then, we review the most relevant pseudocapacitive materials in \\ aqueous and non-aqueous electrolytes. The major challenges for pseudocapacitive materials along with \\ a future outlook are detailed at the end.
}

\begin{abstract}
Broader context
The importance of electrical energy storage will continue to grow as markets for consumer electronics and electrification of transportation expand and energy storage systems for renewable energy sources begin to emerge. There is a need, particularly with transportation and grid storage applications, where large amounts of energy need to be delivered or accepted quickly, within seconds or minutes. Although carbon based electrochemical capacitors possess the required power density, their relatively low energy density limits their usefulness for these applications. Instead, transition metal oxides that exhibit pseudocapacitance are very attractive. Pseudocapacitance occurs when reversible redox reactions occur at or near the surface of an electrode material and are fast enough so that the device's electrochemical features are those of a carbon-based capacitor, but with significantly higher capacitances. It is important to recognize that pseudocapacitance in materials is a relatively new property, with the first materials identified in the 1970's. Thus, both materials systems and electrochemical characteristics which lead to high energy density at high charge-discharge rates are still being identified. To date, transition metal oxides exhibit the widest range of materials with pseudocapacitive behavior. By selecting the proper transition metal oxide, utilizing the most effective electrode architecture, and analyzing the electrochemical behavior for pseudocapacitive behavior, such materials are expected to become the basis for electrochemical energy storage devices which offer high energy density at high rates.
\end{abstract}

\section{Introduction}

Electrochemical energy storage (EES) in the form of batteries and electrochemical capacitors is widely used for powering the now-ubiquitous portable electronics in our society and for the electrification of the transportation sector. The emerging need to overhaul the power grid in many developed countries combined with the expected rise in global energy needs (arising at least partly from the need to electrify developing countries) over the coming decades have brought another application for EES, the coupling of these technologies with renewable energy sources like solar and wind for powering the electrical grid. While opportunities for EES abound, there are several

${ }^{a}$ Department of Materials Science and Engineering, University of California Los Angeles, Los Angeles, CA 90095-1595, USA. E-mail: bdunn@ucla.edu

${ }^{b}$ Department of Materials Science, Université Paul Sabatier, CIRIMAT UMR CNRS 5085, Toulouse, France

'Réseau sur le Stockage Electrochimique de l'Energie (RS2E), FR CNRS 3459, France $\dagger$ Present address: Texas Materials Institute, The University of Texas at Austin, Austin, TX 78712-1591, USA. challenges for these devices that are rooted primarily in finding materials that are better at both storing and delivering large amounts of energy. These functions would ideally be performed by abundant, non-toxic materials in order to also lower the cost and increase the safety of EES devices in consumer products as well as in stationary power.

The current success of EES is in large part due to the use of transition metal oxides in one or both electrodes. This review is concerned with transition metal oxide materials that exhibit pseudocapacitance, which arises when reversible redox reactions occur at or near the surface of a material in contact with an electrolyte, or when these reactions are not limited by solid-state ion diffusion. The behavior can exist in both aqueous and non-aqueous electrolytes and can be intrinsic to the material, or extrinsic. The significant difference between battery and pseudocapacitive materials is that the charging and discharging behavior of pseudocapacitive materials occurs on the order of seconds and minutes. Thus a strong motivation for studying and developing pseudocapacitance is that it leads to both high energy and high power densities in the same material. 
Fig. 1 shows the specific energy vs. charging time plot for an electric double layer capacitor (EDLC) and a high-rate lithiumion battery. ${ }^{1}$ This plot clearly demonstrates that a lithium-ion battery optimized for high-power exhibits constant energy density for discharge times $>10$ minutes. At shorter timescales, this energy decreases due to the various resistive losses within a battery cell, mainly stemming from sluggish electron and ion transport. These resistive losses, particularly at high rates, give rise to heat generation which can lead to serious safety problems such as thermal runaway. ${ }^{2}$ On the other hand, commercially-available EDLCs exhibit constant energy densities for all timescales but their total stored energy is low. In between the regimes where EDLCs and lithium-ion batteries exhibit their best performance is a time domain ( $\sim 10 \mathrm{~s}$ to 10 minutes) that appears well-suited for the pseudocapacitive materials described in this review.

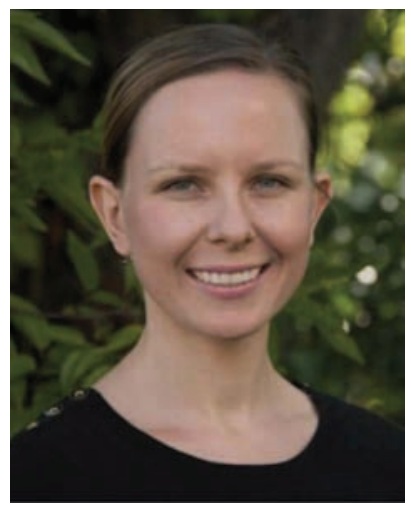

Veronica Augustyn received her Ph.D. degree in Materials Science and Engineering under the supervision of Prof. Bruce Dunn from the University of California, Los Angeles, in 2013. She is currently a Postdoctoral Fellow at the University of Texas at Austin, working in the laboratory of Prof. Arumugam Manthiram. Her current research interests include the design, synthesis, and characterization of novel transition-metal based materials for electrochemical energy storage and electrocatalysis.

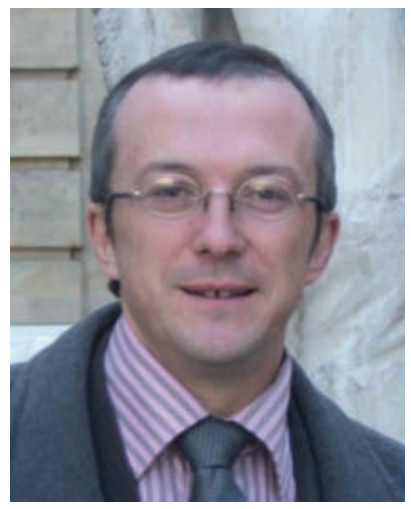

Patrice Simon is Professor of Materials Science at the Université Paul Sabatier in Toulouse, France. His research interests are in the synthesis and electrochemical characterization of materials for supercapacitors and batteries. An important part of his work focuses on the development of porous carbon structures and the study of ion confinement and dynamics in carbon micropores. Professor Simon has received several awards for his work including an Advanced Grant from the European Research Council (ERC) in 2011 and the Tajima Prize of the International Electrochemical Society (2009). Together with Prof. Jean-Marie Tarascon, he leads the French network on Electrochemical Energy Storage (RS2E).

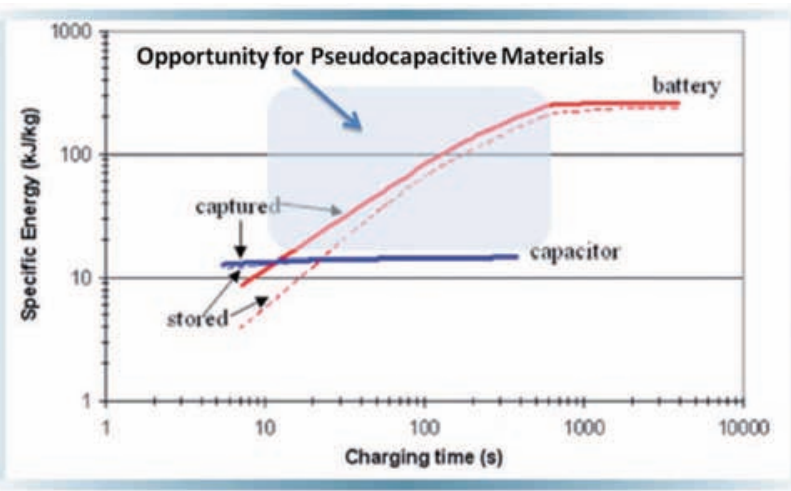

Fig. 1 Energy vs. charging time for an EDLC and a lithium-ion battery. ${ }^{1}$ The region between $\sim 10 \mathrm{~s}$ and 10 minutes represents the time domain where high-rate pseudocapacitive materials could offer higher energy and power densities than lithium-ion batteries and EDLCS. Reproduced by permission of The Electrochemical Society.

Such high-rate EES is desirable for numerous applications where a large amount of energy needs to be either stored or delivered quickly. These include kinetic energy harvesting in seaports ${ }^{3}$ or with regenerative braking; ${ }^{4}$ pulse power in communication devices; ${ }^{5}$ and power quality applications in the power grid. ${ }^{6}$ In addition, shorter charging times would be very convenient for portable devices and especially for electric vehicles.

This review is organized into three sections: (a) the background, which details the historical development of pseudocapacitance, the mechanisms that give rise to pseudocapacitance, and the electrochemical features of this behavior; (b) materials that exhibit pseudocapacitance in aqueous electrolytes; and (c) materials that exhibit pseudocapacitance in non-aqueous electrolytes. In order to aid in the comparison of the different materials, capacity and capacitance values as well as the time of

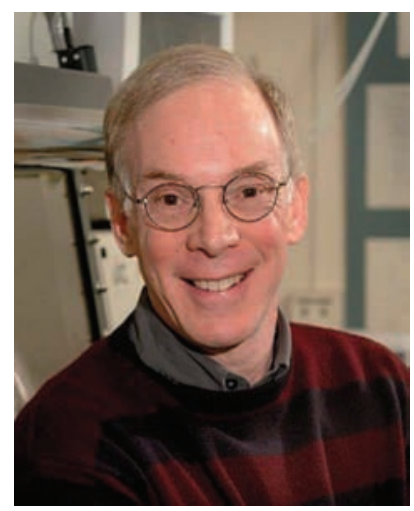

Bruce Dunn is the Nippon Sheet Glass Professor of Materials Science and Engineering at UCLA. Prior to joining UCLA in 1981, he was a staff scientist at the General Electric Research Laboratory. His research interests are in the synthesis of inorganic and organic/inorganic materials, and the design of their electrochemical, optical and biochemical properties. His current programs in electrochemistry include creating pseudocapacitive materials and the fabrication of three-dimensional batteries. Professor Dunn has received a number of honors including a Fulbright research fellowship, invited professorships at the University of Paris, the University of Bordeaux and two awards from the Department of Energy for Outstanding Research in Materials Science. He is a Fellow of the American Ceramic Society and the Materials Research Society. 
the experiment are reported as often as possible. The incorporation of pseudocapacitive materials in electrode structures can result in dramatic differences for certain materials, and this is highlighted when appropriate. While it has been known for some time what electrochemical features are indicative of pseudocapacitance, a clear understanding of the mechanisms and the manner in which these depend upon the redox chemistry and structure of the material is an area of active investigation.

\section{Background}

While the idea that charges could accumulate on solids was known since ancient times, (dating back to the Greek word for amber - electron $)^{7}$ the first patent for an electrochemical capacitor was not filed until 1957 by General Electric. ${ }^{8}$ This was a relatively late entry into the energy storage field because, with the exception of the lithium-ion battery, most energy storage devices were invented by the end of the $19^{\text {th }}$-early $20^{\text {th }}$ century. The patent contains an interesting statement: "it is not positively known exactly what takes place when the devices [...] are used as energy storing devices". It should be noted that the need for a high surface area electrode was identified. Today it is known that such devices store charge through the adsorption of electrolyte ions onto the surfaces of electrified materials, and that carbons are ideal materials due to the combination of high conductivity, large surface areas, and low density. This type of charge storage is electrostatic and no redox reactions are involved. Such devices are called electric double-layer capacitors (EDLCs) and commercial devices can store between 3 and $6 \mathrm{~W} \mathrm{~h} \mathrm{~kg}^{-1}$.9

The field of EDLCs has been the subject of numerous reviews over the past few years..$^{\mathbf{1 0}-12}$ A major research objective in the field of EDLCs is to understand the dependence of electrode area, including pore structure, on the capacitance. ${ }^{13}$ Currently, the best carbon materials achieve double-layer capacitances of approximately $150 \mathrm{~F} \mathrm{~g}^{-1}$ for optimum carbon pore sizes in ionic liquid electrolytes. ${ }^{14}$ Strategies for improving the energy densities of EDLCs include functionalizing the surface with nitrogen and oxygen groups ${ }^{15}$ utilizing pore sizes that match the electrolyte ion size, ${ }^{16}$ using redox-active species in the electrolyte, ${ }^{17}$ or designing ionic liquid mixtures for improving the cell voltage and temperature range. ${ }^{18}$ The prospect of using graphene for EDLCs has generated considerable interest in the community. The high surface area of graphene has led to specific capacitances in the range of $100-250 \mathrm{~F} \mathrm{~g}^{-1} \cdot{ }^{19,20}$ However, because of the nanoscale sheet-like morphology of these materials, there is a concern that the gravimetric-normalized capacitance may not be a useful metric. ${ }^{21}$ Nonetheless, graphene has been particularly effective in the development of flexible device architectures for EDLCs.

\subsection{Development of pseudocapacitance in $\mathrm{RuO}_{2}$}

In 1971, a new type of electrochemical capacitance was discovered in $\mathrm{RuO}_{2}$, termed pseudocapacitance because it involved faradaic charge-transfer reactions..$^{22}$ The storage of protons from the electrolyte resulted in a faradaic charge-transfer reaction on the $\mathrm{RuO}_{2}$ thin film electrode. Despite the faradaic nature of the charge storage process, the cyclic voltammogram $(\mathrm{CV})$ was that of

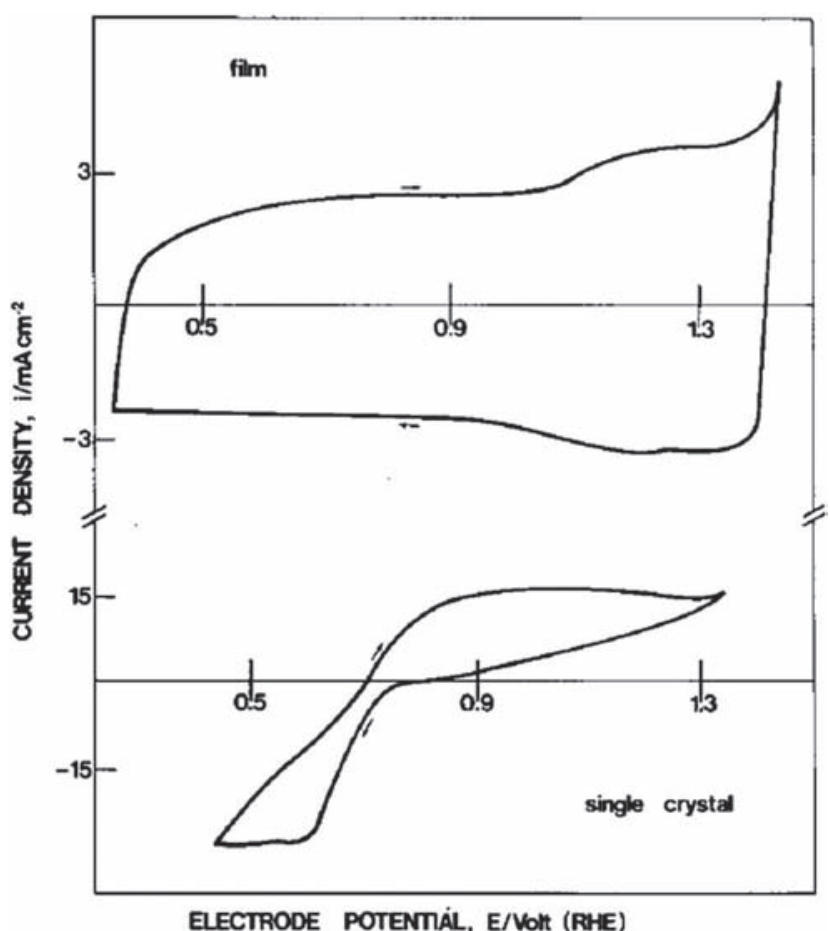

Fig. 2 Cyclic voltammetry at $40 \mathrm{mV} \mathrm{s}^{-1}$ of a $\mathrm{RuO}_{2}$ thin film (top) and single crystal (bottom) in $1 \mathrm{M} \mathrm{HClO}_{4}$. This first investigation of the unique behavior of $\mathrm{RuO}_{2}$ films demonstrated how redox reactions at the surface can give rise to electrochemical features of capacitors. Reprinted from ref. 22, with permission from Elsevier.

a capacitor - i.e. rectangular in shape (Fig. 2). While this first report resulted in low gravimetric capacitance values (only $4-7 \%$ of the $\mathrm{Ru}^{4+}$ atoms participated in the redox reaction), it demonstrated the unique electrochemical features of pseudocapacitive processes. This study also demonstrated the need for a porous and hydrous oxide as the bulk, single-crystal material did not exhibit a rectangular CV. Subsequent studies improved the capacitance to over $700 \mathrm{~F} \mathrm{~g}^{-1}\left(700 \mathrm{C} \mathrm{g}^{-1}, \sim 8.3 \mathrm{~min}\right)$ by identifying the importance of structural water (specifically, $\mathrm{RuO}_{2} \cdot n \mathrm{H}_{2} \mathrm{O}$ where $x=0.5)^{23}$ and a porous, nanoscale architecture. ${ }^{24}$ The storage of protons by hydrated $\mathrm{RuO}_{2}$ can be expressed as: $:^{25}$

$$
\mathrm{RuO}_{x}(\mathrm{OH})_{y}+\delta \mathrm{H}^{+}+\delta \mathrm{e}^{-} \leftrightarrow \mathrm{RuO}_{x-\delta}(\mathrm{OH})_{y+\delta}
$$

and when $\delta=2$ this results in a maximum theoretical capacitance of $1450 \mathrm{~F} \mathrm{~g}^{-1}$ of $\mathrm{RuO}_{2}\left(1360 \mathrm{~F} \mathrm{~g}^{-1}\right.$ of $\left.\mathrm{RuO}_{2} \cdot 0.5 \mathrm{H}_{2} \mathrm{O}\right)$ over a $1 \mathrm{~V}$ window.

$\mathrm{RuO}_{2} \cdot 0.5 \mathrm{H}_{2} \mathrm{O}$ exhibits four unique features that enable rapid faradaic reactions with high capacitance: (1) the redox behavior of the $\mathrm{Ru}^{4+}$ cation that allows for faradaic energy storage; (2) the metallic conductivity of $\mathrm{RuO}_{2}$ that allows for rapid electron transport; (3) the presence of structural water that enables rapid proton transport within the so-called "inner surface"; and (4) a large "outer" surface area that decreases diffusion distances. Unfortunately, the high cost of ruthenium (currently at $\sim 2000$ USD per $\mathrm{kg}$ ) makes devices based on $\mathrm{RuO}_{2}$ impractical for widespread application, except in small-size devices such as 
microsupercapacitors. Nevertheless, the behavior of hydrous $\mathrm{RuO}_{2}$ first demonstrated that in certain systems, reversible faradaic reactions can result in similar electrochemical features as those of a capacitor. The study of $\mathrm{RuO}_{2}$ also led to the understanding of what constitutes an ideal pseudocapacitive material in aqueous electrolytes.

\subsection{Types of pseudocapacitive mechanisms}

Conway identified several faradaic mechanisms that can result in capacitive electrochemical features: ${ }^{7}$ (1) underpotential deposition, (2) redox pseudocapacitance (as in $\mathrm{RuO}_{2} \cdot n \mathrm{H}_{2} \mathrm{O}$ ), and (3) intercalation pseudocapacitance. These processes are illustrated in Fig. 3. Underpotential deposition occurs when metal ions form an adsorbed monolayer at a different metal's surface well above their redox potential. One classic example of underpotential deposition is that of lead on the surface of a gold electrode. $^{26}$ Redox pseudocapacitance occurs when ions are electrochemically adsorbed onto the surface or near surface of a material with a concomitant faradaic charge-transfer. Intercalation pseudocapacitance occurs when ions intercalate into the tunnels or layers of a redox-active material accompanied by a faradaic charge-transfer with no crystallographic phase change. These three mechanisms occur due to different physical processes and with different types of materials; the similarity in the electrochemical signatures occurs due to the relationship between potential and the extent of charge that develops as a result of adsorption/desorption processes at the electrode/ electrolyte interface or within the inner surface of a material: ${ }^{27}$

$$
E \sim E^{0}-\frac{R T}{n F} \ln \left(\frac{X}{1-X}\right)
$$

here, $E$ is the potential (V), $R$ is the ideal gas constant $(8.314 \mathrm{~J}$ $\left.\mathrm{mol}^{-1} \mathrm{~K}^{-1}\right), T$ is the temperature (K), $n$ is the number of electrons, $F$ is the Faraday constant $\left(96485 \mathrm{C} \mathrm{mol}^{-1}\right.$ ), and $X$ is the extent of fractional coverage of the surface or inner structure. In eqn (2), a capacitance $\left(C ; \mathrm{F} \mathrm{g}^{-1}\right)$ may be defined in regions where the plot of $E$ vs. $X$ is linear:

$$
C=\left(\frac{n F}{m}\right) \frac{X}{E}
$$

where $m$ is the molecular weight of the active material. Since the plot of $E$ vs. $X$ is not entirely linear as in a capacitor,

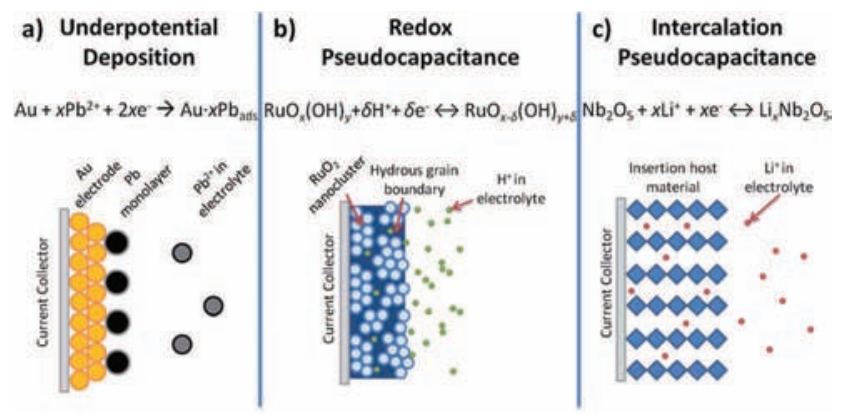

Fig. 3 Different types of reversible redox mechanisms that give rise to pseudocapacitance: (a) underpotential deposition, (b) redox pseudocapacitance, and (c) intercalation pseudocapacitance. the capacitance is not always constant and so it is termed pseudocapacitance.

While the above relationship describes the thermodynamic basis for pseudocapacitance, the utility of such materials for energy storage is in their kinetic behavior. This stems from the fact that reactions that occur at the surface, or are limited by the surface, are not limited by solid-state diffusion and therefore exhibit high rate capability. This is an important difference between transition metal oxides that exhibit pseudocapacitive behavior and those that do not. The latter are materials that are utilized in rechargeable batteries, where the use of the bulk solid state to store charge results in high energy densities. However, in these devices the power capability is limited by the solid-state diffusion within the cathode and anode active materials. ${ }^{2}$

\subsection{Electrochemical features of pseudocapacitance}

Pseudocapacitance can result from various processes as mentioned previously. Electrochemically, pseudocapacitance gives rise to specific features as presented in this section. We describe pseudocapacitive energy storage on the basis of its response to (a) a voltage sweep, as in cyclic voltammetry; (b) constant current, as in galvanostatic cycling, and (c) alternating current, as in impedance spectroscopy.

In a cyclic voltammetry experiment, the timescale of the experiment is controlled by the sweep rate $\left(v, \mathrm{mV} \mathrm{s}^{-1}\right)$. The current response to an applied sweep rate will vary depending on whether the redox reaction is diffusion-controlled or surfacecontrolled (capacitive). For a redox reaction limited by semiinfinite linear diffusion, the current response varies with $v^{1 / 2}$; for a capacitive process, the current varies directly with $v$. Therefore, for any material the following general relationship may be written for the current at a particular potential: ${ }^{28}$

$$
i(V)=k_{1} v^{1 / 2}+k_{2} v
$$

Solving for the values of $k_{1}$ and $k_{2}$ at each potential allows for the separation of the diffusion and capacitive currents. Care should be taken in utilizing this mathematical treatment as the current relationships do not establish the mechanism: this should be corroborated with other characterization techniques. The technique has been utilized to evaluate the performance of novel nanostructured materials, ${ }^{29-32}$ as shown in the example in Fig. 4.

A related analysis first suggested by Trasatti, et al. ${ }^{34}$ describes the relationship between the capacity and the sweep rate. Capacity that is occurring due to surface processes will be constant with the sweep rate and thus will always be present, even at high sweep rates. Capacity that occurs due to processes limited by semiinfinite linear diffusion will vary with $v^{-1 / 2}$. In the following equation, the capacitive contribution is represented by $Q_{v=\infty}$, which is the infinite-sweep rate capacity; the diffusion-controlled capacity is the remaining contribution, and is limited by $v^{-1 / 2}$ :

$$
Q=Q_{v=\infty}+\text { constant }\left(v^{-1 / 2}\right)
$$

An example of this analysis applied to a coating of $\mathrm{NiCo}_{2} \mathrm{O}_{4}$ is shown in Fig. 5. In this plot of capacity $v s . v^{-1 / 2}$, the extrapolation of the linear fit to the data to the $y$-intercept $\left(v^{-1 / 2}=0\right)$ gives 


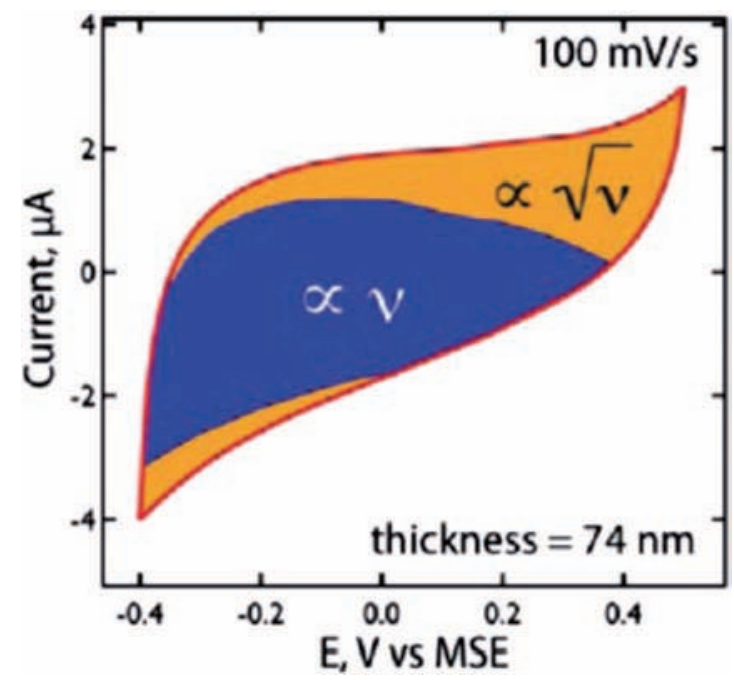

Fig. $4 \mathrm{CV}$ at $100 \mathrm{mV} \mathrm{s}{ }^{-1}$ of $\mathrm{Au} / \mathrm{MnO}_{2}$ core-shell nanowires separated into capacitive (varying with $v$ ) and diffusion (varying with $v^{1 / 2}$ ) contributions utilizing the analysis based on eqn (4). Reprinted with permission from ref. 33. Copyright 2012 American Chemical Society.

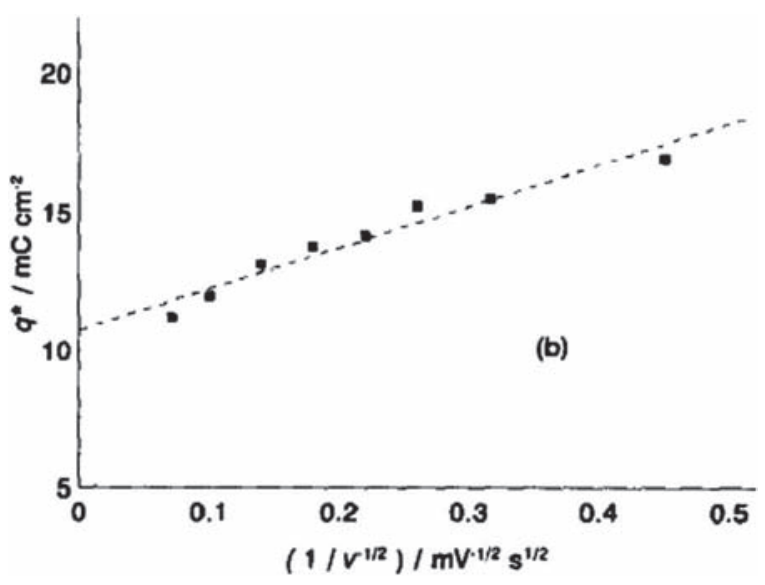

Fig. 5 Kinetic analysis of the capacity suggested by Trasatti et al. The example here is of $\mathrm{NiCO}_{2} \mathrm{O}_{4}$ deposited on Ti with an interlayer of $\mathrm{RuO}_{2}$. In the plot of capacity $\left(q^{*}\right)$ vs. $v^{-1 / 2}$, the $y$-intercept corresponds to the infinite sweep rate capacity, $Q_{v=\infty}$. Reprinted from ref. 35, with permission from Elsevier.

$Q_{v=\infty}$. Here, $Q_{v=\infty}$ is $\sim 10.5 \mathrm{mC} \mathrm{cm}^{-2}$ which represents the contribution of the so-called outer surface of $\mathrm{NiCo}_{2} \mathrm{O}_{4}$ to the charge storage. At $5 \mathrm{mV} \mathrm{s}^{-1}$, the outer surface of $\mathrm{NiCo}_{2} \mathrm{O}_{4}$ contributes $\sim 62 \%$ of the total capacity.

Another feature of rapid energy storage is the relationship between peak potential and sweep rate. ${ }^{36}$ In a capacitive system, there is very little potential hysteresis between the charging and discharging steps particularly for slow charge-discharge times. In a cyclic voltammetry experiment, this translates into a small or no potential difference between the anodic and cathodic peak currents at slow sweep rates, as shown in Fig. 6 for a film of $30 \mathrm{~nm}$ $\mathrm{Nb}_{2} \mathrm{O}_{5}$ nanocrystals. A small potential difference in a Nernstian process also indicates that the reaction is reversible and in such a reaction, the peak voltage difference is $59 \mathrm{mV}^{-1}$, where $n$ is the

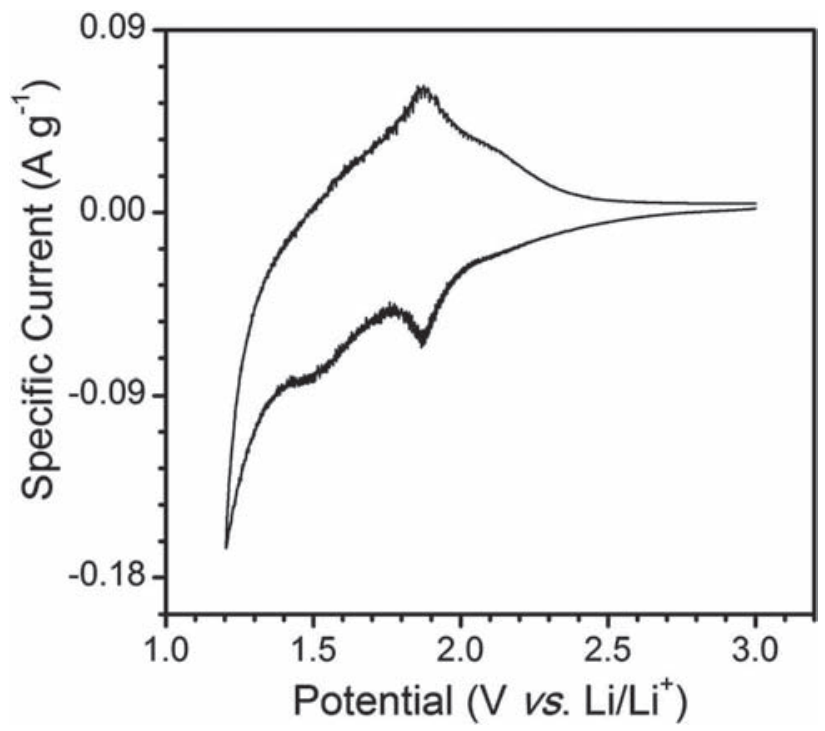

Fig. $6 \mathrm{CV}$ of $\mathrm{Nb}_{2} \mathrm{O}_{5}$ nanocrystals at $0.1 \mathrm{mV} \mathrm{s}^{-1}$ in a non-aqueous lithium ion electrolyte. At this rate, the peak voltages for lithium insertion/de-insertion overlap, a characteristic of materials which exhibit rapid energy storage kinetics. ${ }^{38}$

number of electrons involved. ${ }^{37}$ This behavior in transition metal oxides is indicative of there being rapid energy storage with no phase change, or, in rare cases, that the phase change occurs with a very small volume change between the charged and discharged phases. It should be noted that polarization processes will lead to peak voltage separation in all electrochemical systems; eqn (4) and (5) above are utilized in regions where the polarization is not significant. For thin films of transition metal oxides, this means that the experiment is performed at sweep rates of $<100 \mathrm{mV} \mathrm{s}^{-1}$, and usually between 1 and $10 \mathrm{mV} \mathrm{s}^{-1}$.

In a constant current experiment, pseudocapacitance is indicated by a small voltage hysteresis between the charging and discharging steps. Since these materials do not undergo a phase transformation, the profile of potential $v s$. capacity will be almost linear in shape as described by eqn (2) and shown schematically in Fig. 8b as well as in the discharge curve for 6 $\mathrm{nm} \mathrm{LiCoO}{ }_{2}$ nanocrystals in Fig. 9.

AC impedance can also be used to determine whether pseudocapacitive behavior is taking place, although the interpretation of the impedance results is dependent upon the best equivalent circuit for the system. Furthermore, double-layer capacitance and pseudocapacitance may give similar impedance results. The Nyquist representation (real $v s$. imaginary impedance, $Z$ ) for an ideal capacitor is a vertical line, indicating a $90^{\circ}$ phase angle. Deviation from a vertical line to phase angles of $<90^{\circ}$ often occurs and can indicate pseudocapacitive behavior, which is often represented by a constant-phase element in the equivalent circuit: ${ }^{39}$

$$
Z=\frac{1}{B(i \omega)^{p}}
$$

here, $Z$ is the impedance, $B$ is a constant, $\omega$ is the frequency, and $p$ is an adjustable constant. When $p$ is 1 , this corresponds to an ideal capacitor and when $p$ is 0.5 , this indicates semi-infinite diffusion. The impedance behavior of hydrous $\mathrm{RuO}_{2}$ is shown in 

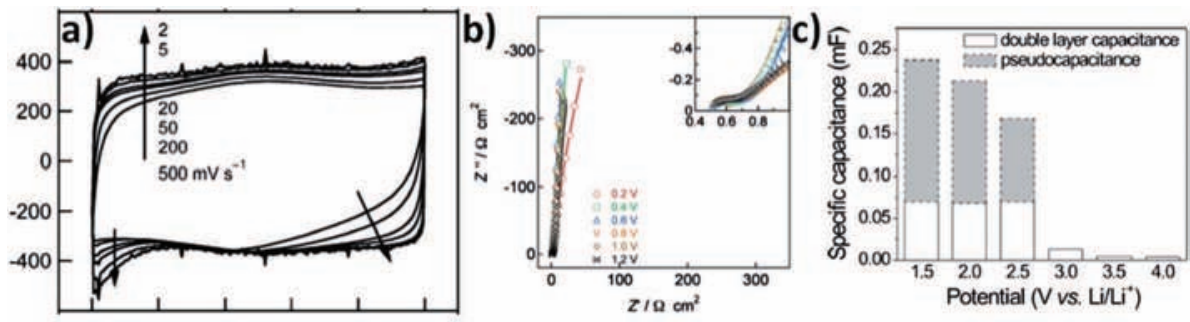

Fig. 7 The utilization of $\mathrm{AC}$ impedance in analyzing pseudocapacitive behavior: (a) CVs of $\mathrm{RuO}_{2} \cdot 0.5 \mathrm{H}_{2} \mathrm{O}$ in $0.5 \mathrm{M} \mathrm{H}_{2} \mathrm{SO}_{4}$ and (b) $\mathrm{Nyquist}_{\text {(complex }}$ impedance) plot at different potentials during the charging of $\mathrm{RuO}_{2} \cdot 0.5 \mathrm{H}_{2} \mathrm{O}$. The impedance results demonstrate that this material has relatively small deviations from ideal capacitor behavior. (c) Results of the equivalent circuit fitting of impedance data for mesoporous $\mathrm{CeO}_{2}$ in $1 \mathrm{M} \mathrm{LiClO}_{4}$ in propylene carbonate. Reprinted with permission from (a \& b) ref. 41 and (c) ref. 40. Copyright 2005 \& 2010 American Chemical Society.
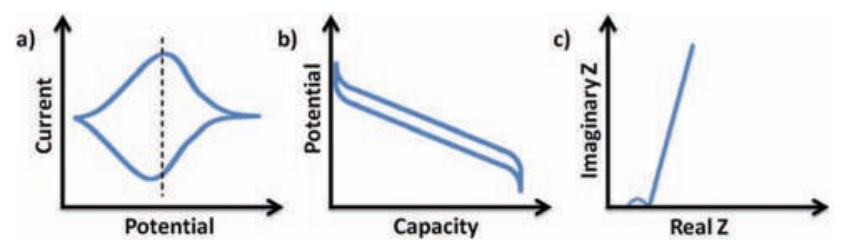

Fig. 8 The general electrochemical features of pseudocapacitive materials. (a) In a cyclic voltammetry experiment, the shape is rectangular and if peaks are present, they are broad and exhibit a small peak-to-peak voltage separation. (b) In a galvanostatic experiment, the shape is sloping so that a capacitance value, $\Delta Q / \Delta E$, may be assigned at each point, and the voltage hysteresis is small. Here, $Q$ is the capacity and $E$ is the potential window. (c) In an AC impedance experiment, the Nyquist representation will contain a vertical line with a phase angle of $90^{\circ}$ or less. A semi-circle at high frequencies, associated with charge-transfer resistance, may also be present.

Fig. 7b. Analysis of impedance behavior has also been used to separate the double layer and pseudocapacitive contributions to charge storage in a mesoporous $\mathrm{CeO}_{2}$ electrode at different potentials in a non-aqueous lithium-ion electrolyte. ${ }^{40}$ It is interesting to compare the impedance behavior of the mesoporous $\mathrm{CeO}_{2}$ with that of hydrous $\mathrm{RuO}_{2}$. In the case of $\mathrm{RuO}_{2}$, the Nyquist plots (Fig. 7b) are similar for a broad range of potentials, from 0.2 to $1.2 \mathrm{~V}$. On the other hand, for mesoporous $\mathrm{CeO}_{2}$ (Fig. 7c), the impedance is potential-dependent due to the fact that in this material, the charge storage is due to potentialdependent $\mathrm{Li}^{+}$intercalation.

Materials that do not exhibit any of these electrochemical features are not pseudocapacitive, and it is questionable whether capacitance values should be used to characterize their electrochemical charge storage behavior. The electrochemical behavior of materials believed to be pseudocapacitive should be carefully analyzed to determine if pseudocapacitance is present. Fig. 8 summarizes the general electrochemical features of pseudocapacitive materials. In the following sections, the electrochemical behavior of various pseudocapacitive materials will be revisited and discussed in light of the key features presented above.

\subsection{Intrinsic vs. extrinsic pseudocapacitance}

Pseudocapacitance can be intrinsic to a material or extrinsic, in that the property can emerge through appropriate material engineering. Regardless of whether a material is considered to be an intrinsic or extrinsic pseudocapacitor, it exhibits the features described in the prior section. Intrinsic pseudocapacitive materials display the characteristics of capacitive charge storage for a wide range of particle sizes and morphologies. These are materials such as $\mathrm{RuO}_{2} \cdot n \mathrm{H}_{2} \mathrm{O},{ }^{23} \mathrm{MnO}_{2},{ }^{42}$ and $\mathrm{Nb}_{2} \mathrm{O}_{5} \cdot{ }^{38}$ On the other hand, extrinsic materials do not exhibit pseudocapacitance in the bulk state due to phase transformations during ion storage. With these materials, increasing the surface area through nanostructuring leads to improved high-rate behavior due to a decrease in diffusion distances and in some cases, the suppression of a phase transformation. These two factors are exhibited by a number of transition metal oxides. For example, bulk $\mathrm{LiCoO}_{2}$ exhibits a voltage plateau during lithium insertion with an average voltage of about $3.9 \mathrm{~V}$. Reducing the particle dimension to $17 \mathrm{~nm}$ or less reduces the voltage plateau in favor of a continuously sloping voltage profile over the entire intercalation range, with nanocrystals of $6 \mathrm{~nm}$ exhibiting an almost linear discharge curve (Fig. 9). ${ }^{43}$

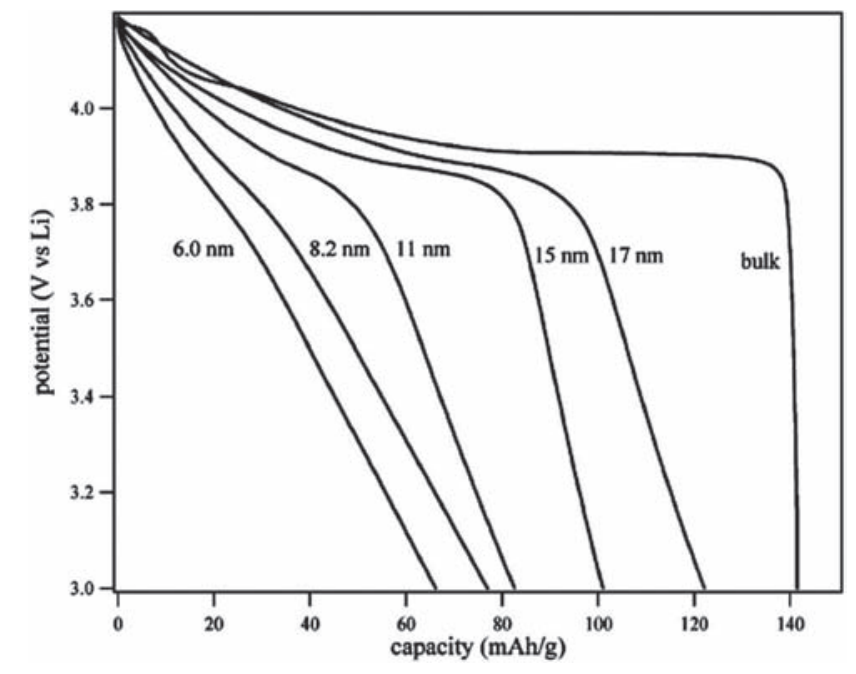

Fig. 9 The effect of crystallite size on the lithiation (discharge) curve of $\mathrm{LiCOO}$ measured for a 1 hour charge-discharge. For small crystallite sizes the plateau region decreases and is replaced by a completely sloping voltage profile. For $6 \mathrm{~nm}$ crystallites, the voltage profile is almost linear in shape; this is due to the increased contribution of surface lithium ion storage sites. Reprinted with permission from ref. 43. Copyright 2007 American Chemical Society. 


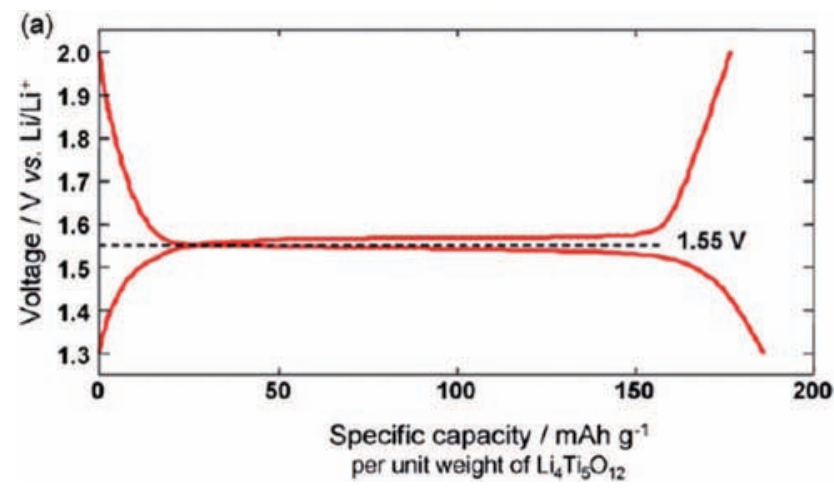

Fig. 10 Charge-discharge curve of nanocrystalline $(5-20 \mathrm{~nm})$ $\mathrm{Li}_{4} \mathrm{Ti}_{5} \mathrm{O}_{12}$ attached to carbon nanofibers cycled at a 1 hour chargedischarge time. Unlike in $\mathrm{LiCOO}_{2}$, nanostructuring does not lead to a sloping voltage profile. Reprinted from ref. 47, with permission from Elsevier.

The change in behavior from a flat discharge curve, as expected for a bulk material undergoing a phase transformation during a redox reaction, to a sloping one was attributed to the increased contribution of surface lithium ion storage sites in nanostructured $\mathrm{LiCoO}_{2}$. The site energy for an intercalated lithium ion is expected to take on a range of values due to the structural disorder for the layers near the surface, and this translates to a discharge curve that is similar to the type described by eqn (2). As a result of the increased number of lithium storage sites near the surface, the rate capability of $17 \mathrm{~nm}$ nanocrystals was superior to that of bulk $(\sim 200 \mathrm{~nm}) \mathrm{LiCoO}_{2}$. This example demonstrates how pseudocapacitance can emerge when a material is engineered so that a large percentage of the lithium ion storage sites are limited to the surface by nanostructuring the material. In addition to $\mathrm{LiCoO}_{2}$, battery materials that exhibit significant pseudocapacitance when nanostructured include $\mathrm{V}_{2} \mathrm{O}_{5}$ and nickel and cobalt hydroxides.

Materials that undergo crystallographic phase transformations during electrochemical cycling usually do not exhibit high rate behavior and there is a significant voltage hysteresis between the charge and discharge steps. An example of this behavior is $\mathrm{LiMn}_{2} \mathrm{O}_{4}$, where the de-insertion/insertion of lithium occurs between two distinct phases, the spinel $\mathrm{LiMn}_{2} \mathrm{O}_{4}$ and the metastable spinel $\lambda-\mathrm{MnO}_{2}$, with an overall unit cell volume change of $7.6 \%{ }^{44}$ The intercalation of lithium ions within the spinel $\mathrm{Li}_{4} \mathrm{Ti}_{5} \mathrm{O}_{12}$ is an exception to this trend because here, the phase transformation occurs with zero strain. ${ }^{45}$ This unique behavior occurs due to the very close structural relationship between the two different phases, $\mathrm{Li}_{4} \mathrm{Ti}_{5} \mathrm{O}_{12}$ and $\mathrm{Li}_{7} \mathrm{Ti}_{5} \mathrm{O}_{12}$, the latter being the fully lithiated phase, that results in a volume change of less than $0.2 \% .{ }^{46}$ Electrodes of $\mathrm{Li}_{4} \mathrm{Ti}_{5} \mathrm{O}_{12}$ nanocrystals with a diameter of $8 \mathrm{~nm}$ do not exhibit a sloping voltage plateau, suggesting that nanostructuring has little influence on the lithium ion storage site energy, as can be expected from a two-phase system (Fig. 10). Thus far, it appears that $\mathrm{Li}_{4} \mathrm{Ti}_{5} \mathrm{O}_{12}$ is the only material to exhibit the phenomenon of zero-strain intercalation in a material that undergoes a phase change during lithiation. It is not a pseudocapacitive material as a capacitance cannot be defined at a voltage plateau.

\section{Aqueous pseudocapacitor materials}

Many transition metal oxides have been investigated for pseudocapacitive charge storage in aqueous electrolytes. The behavior of these materials depends upon the structure of the material, hydration properties, and the electrolyte. The effect of structural and surface-bound water is one major difference between aqueous and non-aqueous pseudocapacitive materials, as such structural water can result in a large "inner surface" that is available for ion adsorption, as in $\mathrm{RuO}_{2} \cdot n \mathrm{H}_{2} \mathrm{O}$. The structural water may also aid in ion diffusion into the inner surface. Here, we will review the most important pseudocapacitive materials in aqueous electrolytes: $\mathrm{MnO}_{2}, \mathrm{RuO}_{2} \cdot n \mathrm{H}_{2} \mathrm{O}$, oxides with the spinel structure such as $\mathrm{Mn}_{3} \mathrm{O}_{4}$, and transition metal hydroxides. $\mathrm{MnO}_{2}$ exists in a number of polymorphs and most have been investigated for pseudocapacitive behavior. Spinel oxides share a common structure but exhibit very different behavior based on the transition metal(s) involved. Finally, the hydroxides exhibit extrinsic pseudocapacitance, as their battery-type behavior becomes increasingly pseudocapacitive with nanostructuring. $\mathrm{MnO}_{2}$, the most widely studied pseudocapacitor material, is reviewed first.

\section{1. $\mathrm{MnO}_{2}$}

The pseudocapacitive behavior of $\mathrm{MnO}_{2}$ was first investigated in 1999 by Lee and Goodenough as they studied the properties of amorphous $\mathrm{MnO}_{2} \cdot n \mathrm{H}_{2} \mathrm{O}$ in a $\mathrm{KCl}$ aqueous electrolyte. ${ }^{48}$ The presence of a rectangular voltammogram and the storage of approximately $200 \mathrm{~F} \mathrm{~g}^{-1}\left(240 \mathrm{C} \mathrm{g}^{-1}, 4 \mathrm{~min}\right)$ indicated that rapid faradaic reactions were responsible for charge storage in this material, as shown in Fig. 11a. In general, pseudocapacitive charge storage of $\mathrm{MnO}_{2}$ in an aqueous electrolyte occurs through the redox of $\mathrm{Mn}$ between the +4 and +3 oxidation states at the surface or in the bulk: ${ }^{49}$

$$
\mathrm{MnO}_{2}+x \mathrm{~A}^{+}+x \mathrm{e}^{-} \leftrightarrow \mathrm{A}_{x} \mathrm{MnO}_{2}
$$

here, A represents an alkali metal cation. Theoretically, the 1electron redox reaction $(x=1)$ corresponds to $1233 \mathrm{~F} \mathrm{~g}^{-1}(1110$ $\mathrm{C} \mathrm{g}^{-1}$ ) assuming a $0.9 \mathrm{~V}$ potential window. $\mathrm{MnO}_{2}$ is abundant and low cost, which makes it particularly appealing when compared to $\mathrm{RuO}_{2}$. However, $\mathrm{MnO}_{2}$ does not possess the high electronic conductivity of $\mathrm{RuO}_{2}\left(10^{4} \mathrm{~S} \mathrm{~cm}^{-1}\right.$ for bulk single crystal): depending on the crystal structure, the conductivity of $\mathrm{MnO}_{2}$ ranges from $10^{-7}$ to $10^{-3} \mathrm{~S} \mathrm{~cm}^{-1} .^{50}$ As a result, charge storage in $\mathrm{MnO}_{2}$ occurs within a thin layer of the surface. ${ }^{49}$ This translates into capacitance values that are significantly lower from the theoretical value for thick composite electrodes, where typical specific capacitances range between 200 and $250 \mathrm{~F} \mathrm{~g}^{-1}$, while still exhibiting the pseudocapacitive electrochemical signature in cyclic voltammetry or galvanostatic experiments. On the other hand, it has been shown that ultrathin films of $\mathrm{MnO}_{2}$ can achieve specific capacitances of $>1000 \mathrm{~F} \mathrm{~g}^{-1,33,49}$ demonstrating that nanostructuring is a highly effective method for accessing all of the $\mathrm{MnO}_{2}$ storage sites. The various 

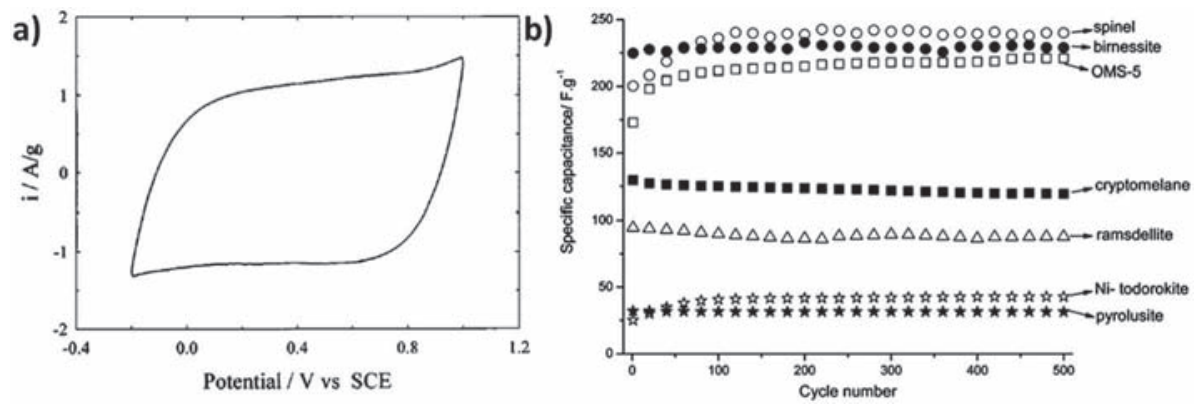

Fig. 11 (a) $\mathrm{CV}$ at $5 \mathrm{mV} \mathrm{s}{ }^{-1}$ of a thick composite electrode of amorphous $\mathrm{MnO}_{2} \cdot n \mathrm{H}_{2} \mathrm{O}$ in $2 \mathrm{M} \mathrm{KCl}$ electrolyte. At this sweep rate, the capacitance was $\sim 200 \mathrm{~F} \mathrm{~g}^{-1}$. Reprinted from ref. 48, with permission from Elsevier. (b) The specific capacitance and cyclability of different $\mathrm{MnO}_{2}$ allotropes under investigation for high-rate energy storage as tested in a composite electrode architecture in $0.5 \mathrm{M} \mathrm{K}_{2} \mathrm{SO}_{4}$ electrolyte at $5 \mathrm{mV} \mathrm{s}$. Reprinted with permission from ref. 50. Copyright 2009 American Chemical Society.

strategies being developed for $\mathrm{MnO}_{2}$ electrodes for electrochemical capacitors have been reviewed. ${ }^{51}$

Both amorphous and crystalline forms of $\mathrm{MnO}_{2}$ have been investigated for high-rate energy storage in aqueous electrolytes. It has been suggested that charge storage in amorphous $\mathrm{MnO}_{2}$ takes place mainly on the surface, while crystalline $\mathrm{MnO}_{2}$ has an additional capacitive contribution from bulk ion intercalation..$^{52}$ However, experimental results demonstrate that in both amorphous and crystalline materials, a high BET surface area does not necessarily lead to high capacitance suggesting that in both types of materials, ions insert into sub-surface sites. Brousse et $a l . .^{42}$ plotted the specific capacitance for a number of crystalline and amorphous $\mathrm{MnO}_{2}$ compounds as a function of surface area. In the case of amorphous materials, the average capacitance was around $160 \mathrm{~F} \mathrm{~g}^{-1}$. Crystalline materials exhibit capacitance values up to $\sim 250 \mathrm{~F} \mathrm{~g}^{-1}$, a bit higher than the amorphous materials, and the fact these are achieved with lower surface areas is indicative of a greater contribution of faradaic reactions to these materials.

The structural chemistry of crystalline $\mathrm{MnO}_{2}$ is very rich, and there are many allotropes. Two different studies ${ }^{50,53}$ reported the effects of crystal structure on the capacitance of $\mathrm{MnO}_{2}$ in aqueous electrolytes (using thick composite electrodes). Both concluded that a wide intercalation tunnel contributes to high capacitance values and that a high BET surface area does not necessarily lead to the best performance. The capacitance as a function of cycle number for different $\mathrm{MnO}_{2}$ allotropes is shown in Fig. 11b. Ghodbane, et al. found the highest capacitance with the spinel form $\left(\lambda-\mathrm{MnO}_{2} ; 245 \mathrm{~F} \mathrm{~g}^{-1} ; 196 \mathrm{C} \mathrm{g}^{-1}, \sim 2.67 \mathrm{~min}\right)$ while Devaraj et al. found the highest capacitance with hollandite $\mathrm{MnO}_{2}\left(\alpha-\mathrm{MnO}_{2} ; 297 \mathrm{~F} \mathrm{~g}^{-1} ; 297 \mathrm{C} \mathrm{g}^{-1} ; \sim 5 \mathrm{~min}\right)$. The different findings are likely due to the use of different synthesis and electrochemical characterization methods. ${ }^{54}$

It is well-known that $\mathrm{Mn}^{3+}$ formed during the redox process disproportionates under acidic, and even near-neutral, conditions. ${ }^{51}$ This can limit the lifetime of devices that utilize $\mathrm{MnO}_{2}$ electrodes. The loss of capacity can be partially mitigated by appropriate electrode and/or cell engineering. For example, by increasing the binder content, thick composite electrodes exhibited only a $5.8 \%$ capacity fade over 1000 cycles at a specific current of $2 \mathrm{~A} \mathrm{~g}^{-1}(\sim 7.5 \mathrm{~s}) .{ }^{55}$ Removing dissolved oxygen from the electrolyte also leads to a marked improvement in the $\mathrm{MnO}_{2}$ cycling stability. ${ }^{56}$

$\mathrm{MnO}_{2}$ exhibits electrochemical features representative of intrinsic pseudocapacitive charge storage. The low cost, abundance, and high theoretical capacitance makes it a very attractive material for aqueous-based electrochemical capacitors. The main challenge for this material is to improve its poor electronic conductivity in order to access the full theoretical capacitance in thick films and at high rates.

\section{2. $\mathrm{RuO}_{2} \cdot n \mathrm{H}_{2} \mathrm{O}$}

As mentioned previously, hydrous $\mathrm{RuO}_{2}$ was the first material to demonstrate pseudocapacitance. While its scarcity and high cost are prohibitive for large-scale applications, there have been significant efforts in fabricating advanced electrodes due to its excellent properties. The motivation for these studies has been to utilize the $\mathrm{RuO}_{2}$ as efficiently as possible by achieving the maximum theoretical capacitance and using as little of the $\mathrm{RuO}_{2}$ as possible. For example, the traditional slurry method with a high $\mathrm{RuO}_{2} \cdot n \mathrm{H}_{2} \mathrm{O}$ mass loading of $\sim 30 \mathrm{mg} \mathrm{cm}{ }^{-2}$ results in a capacitance of $720 \mathrm{~F} \mathrm{~g}^{-1}$ for a charge-discharge time of $\sim 8$ minutes. ${ }^{23}$ This is approximately $50 \%$ of the theoretical capacitance of $\mathrm{RuO}_{2} \cdot n \mathrm{H}_{2} \mathrm{O}$. Utilizing $\mathrm{RuO}_{2}$ nanoparticles dispersed onto activated carbon $\left(10 \mathrm{wt} \% \mathrm{RuO}_{2} \cdot n \mathrm{H}_{2} \mathrm{O} / 90 \mathrm{wt} \%\right.$ activated carbon) leads to capacitances of $1340 \mathrm{~F} \mathrm{~g}^{-1}$ for chargedischarge times of $\sim 1$ minute, ${ }^{57}$ which is much closer to the expected theoretical value. This increase in the capacitance and rate occurs due to the very effective exposure of the $\mathrm{RuO}_{2} \cdot n \mathrm{H}_{2} \mathrm{O}$ to the electrolyte. The drawback to this type of electrode architecture is of course that the total mass loading of $\mathrm{RuO}_{2} \cdot n \mathrm{H}_{2} \mathrm{O}$ per footprint area is low, leading to low areal capacitance values.

\subsection{Oxides with the spinel structure}

The spinel crystal structure, with a general formula $\mathrm{AB}_{2} \mathrm{O}_{4}$, is very important for EES. It offers a robust crystalline architecture with three dimensional diffusion pathways. A number of spinel compounds have been investigated for electrochemical capacitors, including $\mathrm{Mn}_{3} \mathrm{O}_{4},{ }^{58} \mathrm{Fe}_{3} \mathrm{O}_{4},{ }^{59}$ and $\mathrm{Co}_{3} \mathrm{O}_{4},{ }^{60}$ along with mixed transition metal spinels such as $\mathrm{MnFe}_{2} \mathrm{O}_{4},{ }^{61}$ and $\mathrm{NiCo}_{2} \mathrm{O}_{4} \cdot{ }^{62}$ Of these, $\mathrm{Mn}_{3} \mathrm{O}_{4}, \mathrm{Fe}_{3} \mathrm{O}_{4}$, and $\mathrm{MnFe}_{2} \mathrm{O}_{4}$ exhibit the characteristic 
Table 1 Capacitance values of spinel oxides where an oxyhydroxide phase participates in the charge storage mechanism

\begin{tabular}{|c|c|c|c|c|c|}
\hline Material & $\begin{array}{l}\text { Capacitance } \\
\left(\mathrm{F} \mathrm{g}^{-1}\right)\end{array}$ & $\begin{array}{l}\text { Capacity } \\
\left(\mathrm{C} \mathrm{g}^{-1}\right)\end{array}$ & $\begin{array}{l}\text { Charge-discharge } \\
\text { time (s) }\end{array}$ & $\begin{array}{l}\text { Active material mass } \\
\text { loading }\left(\mathrm{mg} \mathrm{cm}^{-2}\right)\end{array}$ & Reference \\
\hline $\mathrm{Co}_{3} \mathrm{O}_{4}$ & 382 & 229 & 115 & 0.5 & 60 \\
\hline \multirow[t]{2}{*}{$\mathrm{NiCo}_{2} \mathrm{O}_{4}$} & 1400 & 672 & 19 & 0.4 & 71 \\
\hline & 678 & 339 & 339 & 8 & 67 \\
\hline $\mathrm{MnCo}_{2} \mathrm{O}_{4}$ & 346 & 173 & 173 & 1 & 68 \\
\hline
\end{tabular}

pseudocapacitive features presented in Fig. 8, including mostly rectangular CVs.

As with $\mathrm{MnO}_{2}$, the poor electronic conductivity of $\mathrm{Mn}_{3} \mathrm{O}_{4}$ leads to low capacitance values for thick electrodes and large particle sizes. For a $1.2 \mu \mathrm{m}$-thick electrode of $\mathrm{Mn}_{3} \mathrm{O}_{4}$ particles (120-140 nm), the cyclic voltammogram is rectangular with a maximum capacitance of $314 \mathrm{~F} \mathrm{~g}^{-1}\left(314 \mathrm{C} \mathrm{g}^{-1} ; 3.3 \mathrm{~min}\right) .{ }^{63}$ The addition of an effective electronically conductive scaffold material such as graphene improves the rate capability at the expense of the specific capacitance, which decreases to $120 \mathrm{~F}$ $\mathrm{g}^{-1}$ when the mass of the scaffold is included..$^{58}$ The mechanism of pseudocapacitive charge storage in $\mathrm{Mn}_{3} \mathrm{O}_{4}$ is not fully established. Recent in situ X-ray absorption near-edge spectra (XANES) experiments have shown that, in a $\mathrm{Na}_{2} \mathrm{SO}_{4}$ electrolyte, the mechanism involves the reversible redox of $\mathrm{Mn}^{3+}$ to $\mathrm{Mn}^{2+}{ }^{64}$ In that study, the highest observed capacitance was $261 \mathrm{~F} \mathrm{~g}^{-1}$ (235 $\mathrm{C} \mathrm{g}^{-1} ; 15 \mathrm{~min}$ ) for $\mathrm{Mn}_{3} \mathrm{O}_{4}$ nanocrystal-film electrodes. A larger capacitance value for $\mathrm{Mn}_{3} \mathrm{O}_{4}$ was found to occur by using a carbon nanotube conductive architecture with $\mathrm{KCl}$ electrolyte. In this case, the specific capacitance was $420 \mathrm{~F} \mathrm{~g}^{-1}\left(294 \mathrm{C} \mathrm{g}^{-1}\right.$; $2.33 \mathrm{~min}) .^{65}$

Only a few reports describe the pseudocapacitive behavior of $\mathrm{MnFe}_{2} \mathrm{O}_{4}$ and $\mathrm{Fe}_{3} \mathrm{O}_{4}$ as the capacitance values of these materials are modest. Crystalline $\mathrm{MnFe}_{2} \mathrm{O}_{4}$ contained in a thick composite electrode architecture exhibits capacitance values of approximately $105 \mathrm{~F} \mathrm{~g}^{-1}$ (94.5 $\mathrm{C} \mathrm{g}^{-1}, 45 \mathrm{~s}$ ) in a $\mathrm{NaCl}$ electrolyte. $^{61,66}$ Its pseudocapacitive mechanism is not clear but is believed to involve redox reactions occurring with both $\mathrm{Mn}$ and

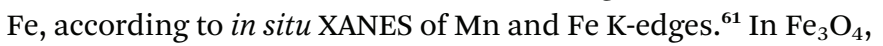
the redox process has been ascribed to the adsorption of anions and the capacitance has been found to be approximately $170 \mathrm{~F}$ $\mathrm{g}^{-1}$ (119 $\mathrm{C} \mathrm{g}^{-1}, 5.8 \mathrm{~min}$ ) for thin films in $\mathrm{Na}_{2} \mathrm{SO}_{3}$ electrolyte. ${ }^{59}$

$\mathrm{Co}_{3} \mathrm{O}_{4},{ }^{60} \mathrm{NiCo}_{2} \mathrm{O}_{4},{ }^{67}$ and $\mathrm{MnCo}_{2} \mathrm{O}_{4}{ }^{68}$ differ from the behavior of the spinel materials described above since they can exhibit battery-type behavior due to the formation of oxyhydroxides during the charge storage process. As shown in Table 1, the reported capacitance values for these materials are significantly larger. This is due to the formation of transition metal oxyhydroxides during the charging process in an alkaline electrolyte, where $\mathrm{M}$ indicates $\mathrm{Ni}, \mathrm{Co}$, or a combination of these: ${ }^{67}$

$$
\mathrm{M}_{3} \mathrm{O}_{4}+\mathrm{OH}^{-}+\mathrm{H}_{2} \mathrm{O} \leftrightarrow 3 \mathrm{MOOH}+\mathrm{e}^{-}
$$

This two-phase reaction (eqn (8)) involves one phase transformation, which results in a constant potential during galvanostatic charge-discharge and also limits the rate capability.
However, when $\mathrm{M}=\mathrm{Co}$, the electrochemically formed oxyhydroxide participates in a second reversible redox process:

$$
\mathrm{CoOOH}+\mathrm{OH}^{-} \leftrightarrow \mathrm{CoO}_{2}+\mathrm{H}_{2} \mathrm{O}+\mathrm{e}^{-}
$$

Fig. 12 demonstrates the presence of several sets of broad redox peaks that have been ascribed to such reactions in $\mathrm{Co}_{3} \mathrm{O}_{4}$. Thus, the electrochemical signature of these materials combines pseudocapacitive (eqn (9)) and battery (eqn (8)) contributions.

$\mathrm{NiCo}_{2} \mathrm{O}_{4}$ exhibits particularly high capacitance values even at short charge-discharge times. This appears to be due to the combination of good electronic conductivity in the discharged material, $\sim 62 \mathrm{~S} \mathrm{~cm}^{-1}$, and utilizing the redox behavior of both nickel and cobalt. ${ }^{67}$ The energy storage properties for $\mathrm{NiCo}_{2} \mathrm{O}_{4}$ have been ascribed to the reversible transformation of the parent spinel compound into nickel and cobalt oxyhydroxides. The cobalt oxyhydroxide is then believed to undergo a second reversible redox reaction, as shown in eqn (9). The theoretical capacity for this overall 3-electron process (per $\mathrm{NiCo}_{2} \mathrm{O}_{4}$ ), including both the pseudocapacitive and the battery-like faradaic contributions, is $1203 \mathrm{C} \mathrm{g}^{-1}$ or $2005 \mathrm{~F} \mathrm{~g}^{-1}$ assuming a typical $0.6 \mathrm{~V}$ potential window in an aqueous alkaline electrolyte. Values close to the theoretical capacitance can be achieved

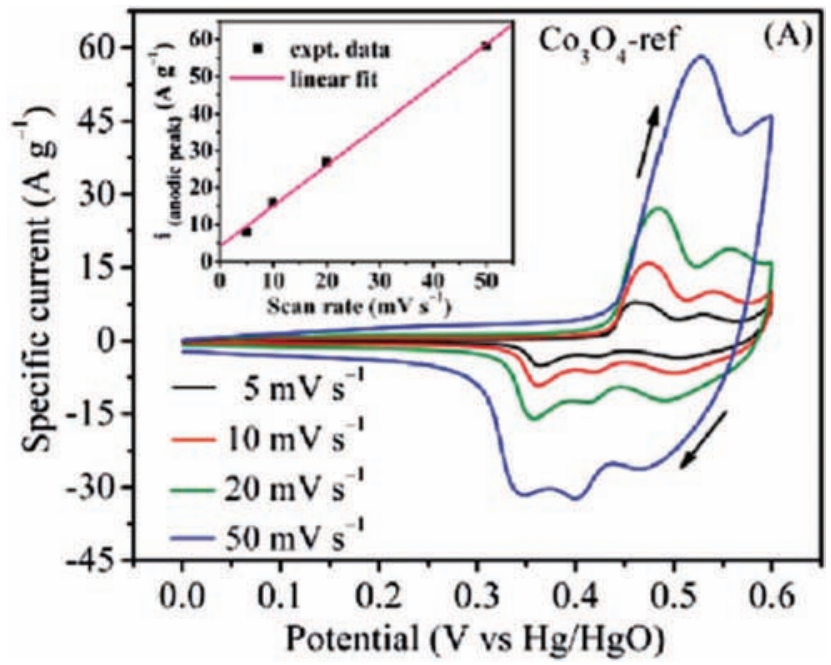

Fig. $12 \mathrm{CVs}$ for a composite electrode consisting of $\mathrm{CO}_{3} \mathrm{O}_{4}$ nanowires in $1 \mathrm{M} \mathrm{KOH}$ from 5 to $50 \mathrm{mV} \mathrm{s}^{-1}$. The inset shows the linear dependence of the anodic peak on the sweep rate, indicative of pseudocapacitive behavior. Reprinted with permission from ref. 69. Copyright 2011 American Chemical Society. 

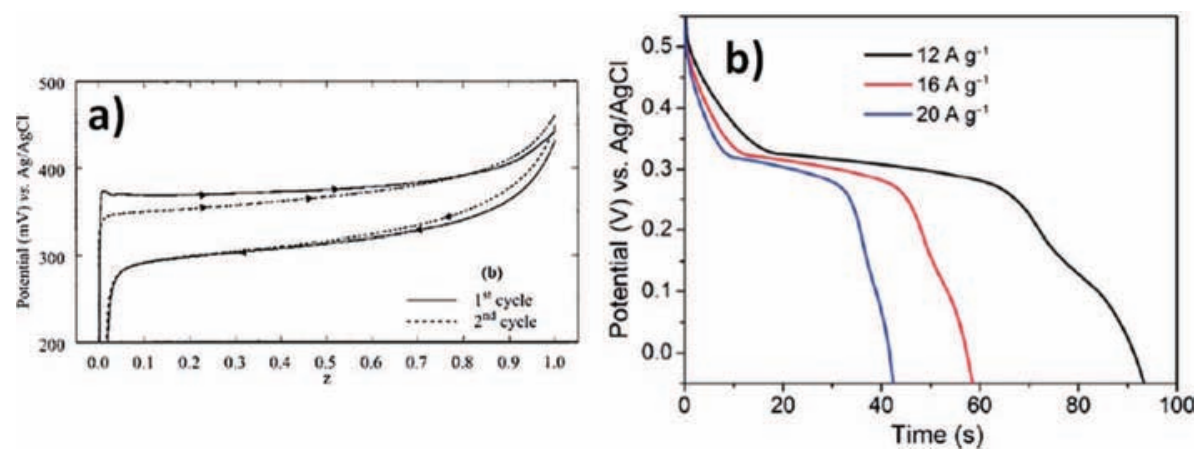

Fig. 13 Comparison of the charge-discharge profiles of $\mathrm{Ni}(\mathrm{OH})_{2}$ in (a) bulk (reproduced from ref. 77 by permission of The Electrochemical Society) and (b) nanostructured forms. The nanostructured electrode contains both the flat battery-type potential region along with sloping pseudocapacitive regions. Reproduced from ref. 78 with permission from The Royal Society of Chemistry.

by using electrode architectures in which $\mathrm{NiCo}_{2} \mathrm{O}_{4}$ nanosheets are electrodeposited onto carbon nanofibers. ${ }^{70}$

The spinel materials described above exhibit both capacitive and battery-type behavior due to the phase changes involved in the cycling process. The preparation of these materials in nanoscale form is expected to emphasize the pseudocapacitive contribution. Thus, in order to improve our understanding of charge storage in these materials, it is important to use the various analyses of kinetics to separate capacitive and diffusion contributions.

\subsection{Nanostructured layered metal hydroxides}

The hydroxides of divalent transition metal oxides, $\mathrm{M}^{2+}(\mathrm{OH})_{2}$, tend to form lamellar structures that generally consist of $\mathrm{MO}_{6}$ octahedra separated by hydrogen atoms. ${ }^{72}$ When some of the transition metals are present in the +3 state, the additional positive charge of the slabs can be compensated by the intercalation of anion species into the interlayer spacing, forming a layered double hydroxide. ${ }^{73}$ In the hydroxides, the interlayer spacing is several $\mathrm{nm}^{74}$ and allows for the reversible intercalation of ions. The nickel and cobalt transition metal hydroxides are an important class of materials that have found commercial application as electrodes in rechargeable aqueous batteries. ${ }^{75}$ Charge storage in these materials involves at least one phase transformation, which results in a constant potential during galvanostatic charge-discharge and also limits the rate capability. Section 2.4 described how pseudocapacitive behavior can emerge when battery materials are nanostructured and energy storage takes place at or near the surface. As a result, nanostructured hydroxides have been investigated as pseudocapacitive electrodes for electrochemical capacitors. These hydroxides can be considered as extrinsic pseudocapacitors as the bulk materials exhibit battery-type behavior.

Charge storage in $\mathrm{Ni}(\mathrm{OH})_{2}$ occurs via reversible redox of the $\mathrm{Ni}^{2+} / \mathrm{Ni}^{3+}$ couple in an alkaline electrolyte, typically $\mathrm{KOH}$ :

$$
\mathrm{Ni}(\mathrm{OH})_{2}+\mathrm{OH}^{-} \leftrightarrow \mathrm{NiOOH}+\mathrm{H}_{2} \mathrm{O}+\mathrm{e}^{-}
$$

This reaction corresponds to a theoretical capacity of $1040 \mathrm{C}$ $\mathrm{g}^{-1}$ within a $0.5 \mathrm{~V}$ potential window. In a suitably nanostructured material, a maximum specific capacitance of $2080 \mathrm{~F} \mathrm{~g}^{-1}$ would be possible. In bulk form, the reaction gives rise to a single pair of redox peaks, which occur at approximately $0.36 \mathrm{~V}(\mathrm{vs} . \mathrm{Ag} / \mathrm{Ag} \mathrm{Cl})$ for the oxidation and $0.26 \mathrm{~V}$ for the reduction. ${ }^{76}$ Fig. 13 shows a qualitative comparison between the charge-discharge profiles of a bulk $\mathrm{Ni}(\mathrm{OH})_{2}$ electrode (Fig. 13a) that exhibits a battery-type potential plateau and a nanostructured electrode (Fig. 13b) which has both a potential plateau and sloping potential regions. The sloping regions at potentials above and below $\sim 0.35$ $\mathrm{V}$ likely correspond to pseudocapacitive contributions from surface or near-surface charge storage. The capacitance of the nanostructured $\mathrm{Ni}(\mathrm{OH})_{2}$ was found to be as high as $1750 \mathrm{~F} \mathrm{~g}^{-1}$, although this value was calculated over the entire potential region, including the battery-type plateau. While the specific capacitance of $\mathrm{Ni}(\mathrm{OH})_{2}$ can be larger than that of $\mathrm{RuO}_{2}$ or $\mathrm{MnO}_{2}$, it occurs over a smaller potential window.

$\mathrm{Co}(\mathrm{OH})_{2}$ can also be cycled in an alkaline electrolyte where the charge storage takes place via reversible redox between $\mathrm{Co}^{2+} /$ $\mathrm{Co}^{3+}$ states. The pseudocapacitive properties of cobalt hydroxide in nanostructured form are not as well explored but appear similar to $\mathrm{Ni}(\mathrm{OH})_{2}$. As with $\mathrm{Ni}(\mathrm{OH})_{2}$, there is a single pair

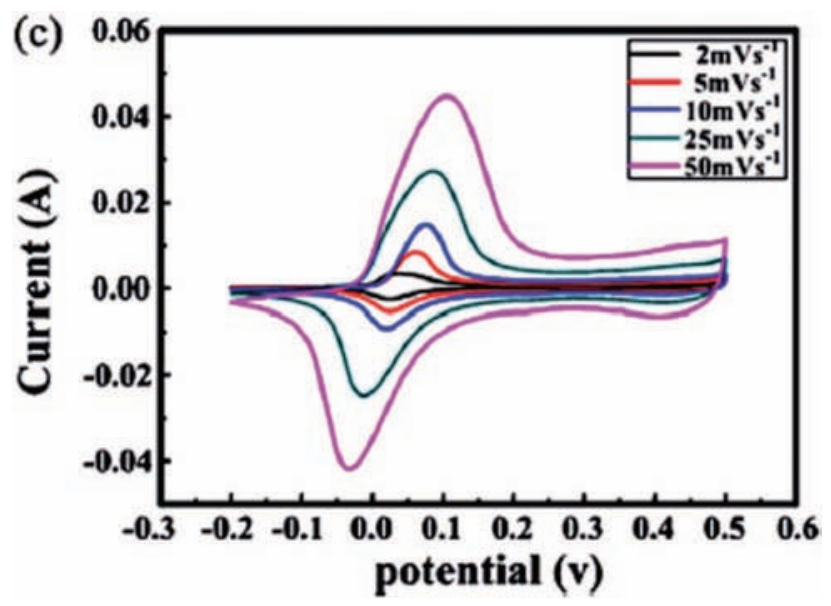

Fig. $14 \mathrm{CVs}$ at various sweep rates for electrodeposited $\mathrm{Co}(\mathrm{OH})_{2}$ on graphene nanosheets. The electrochemical behavior was performed using three-electrode cells in $1 \mathrm{M} \mathrm{KOH}$ electrolyte. Reproduced from ref. 79 with permission from Elsevier. 
of redox peaks over a $0.5 \mathrm{~V}$ potential window. ${ }^{79}$ Fig. 14 demonstrates that when nanostructured, $\mathrm{Co}(\mathrm{OH})_{2}$ exhibits good peak overlap and thus high rate capability. Very high specific capacitances have been reported, up to $2646 \mathrm{~F} \mathrm{~g}^{-1}\left(1455 \mathrm{C} \mathrm{g}^{-1}\right.$ in $\sim 3$ min). ${ }^{80}$ However, as with $\mathrm{Ni}(\mathrm{OH})_{2}$, this capacitance value often includes contributions from battery-type behavior.

\subsection{High-rate performance of aqueous electrolyte pseudocapacitive materials}

In this section, the high-rate performance of different aqueous pseudocapacitive materials is examined. We focus on those studies that demonstrate a charge-discharge time of $\sim 1$ minute. This is relevant for practical device considerations: at timescales greater than about 10 minutes, advanced lithium-ion batteries may be able to provide higher energy densities. Mass loading and electrode porosity greatly influence the rate capability. Designing high-rate electrodes with high active material mass loading and optimum porosity to allow electrolyte access at high rates and sufficient electronic conductivity remains a challenge for all pseudocapacitive materials.

High rate studies have been carried out on several polytypes of $\mathrm{MnO}_{2} \cdot \alpha-\mathrm{MnO}_{2}$ (hollandite) powders in traditional composite electrode architectures (200 $\mu \mathrm{m}$ electrode thickness; $80 \mathrm{wt} \%$ active material mass loading) exhibit a capacitance value of 166 $\mathrm{F} \mathrm{g}^{-1}$ at a sweep rate of $2 \mathrm{mV} \mathrm{s}^{-1}$, which corresponds to a charge-discharge time of 7.5 minutes. ${ }^{81}$ At a sweep rate of $20 \mathrm{mV} \mathrm{s}^{-1}(t=45 \mathrm{~s})$, the capacitance decreases by $40 \%$ to $100 \mathrm{~F}$ $\mathrm{g}^{-1}$. Depositing $\mathrm{MnO}_{2}$ onto a conductive substrate such as carbon nanotubes, ${ }^{82,83}$ graphene,${ }^{84}$ and carbon foam ${ }^{85}$ or forming a thin film ${ }^{49}$ allows for better exposure of the $\mathrm{MnO}_{2}$ surface to the electrolyte and mitigates its poor electronic conductivity. For example, when $\gamma-\mathrm{MnO}_{2}$ (nsutite) was electrodeposited onto carbon nanotubes with a mass loading of $\sim 0.05 \mathrm{mg} \mathrm{cm}{ }^{-2}$, at a sweep rate of $50 \mathrm{mV} \mathrm{s}^{-1}(t=20 \mathrm{~s})$, the capacitance was $\sim 490 \mathrm{~F}$ $\mathrm{g}^{-1}$ over a $1 \mathrm{~V}$ potential window. ${ }^{83}$ Moreover, the current density as a function of the sweep rate was found to be linear from 10 to $150 \mathrm{mV} \mathrm{s}^{-1}$ confirming that the charge storage was pseudocapacitive over a wide timescale. However, $490 \mathrm{~F} \mathrm{~g}^{-1}$ is still less than $50 \%$ of the expected theoretical capacitance of $\mathrm{MnO}_{2}$.

There are several studies reporting very good rate capabilities for the high-capacitance spinel oxides, $\mathrm{MnCo}_{2} \mathrm{O}_{4}$ and $\mathrm{NiCo}_{2} \mathrm{O}_{4}$, and the hydroxides $\mathrm{Ni}(\mathrm{OH})_{2}$ and $\mathrm{Co}(\mathrm{OH})_{2}$. For example, at a high active material mass loading of $8 \mathrm{mg} \mathrm{cm}^{-2}$ and utilizing a traditional composite electrode architecture, the capacitance of $\mathrm{NiCo}_{2} \mathrm{O}_{4}$ was found to be $630 \mathrm{~F} \mathrm{~g}^{-1}$ for a charge-discharge time of 1 minute. ${ }^{67}$ Amorphous $\mathrm{Ni}(\mathrm{OH})_{2}$ nanosheets electrodeposited onto graphite, with a mass loading of $0.12 \mathrm{mg} \mathrm{cm}^{-2}$, give a very high extrinsic capacitance of $1500 \mathrm{~F} \mathrm{~g}^{-1}$ at a charge-discharge time of 1 minute. ${ }^{86}$ The challenge with these materials is not only to achieve a high specific capacitance at a short timescale, but also to broaden their typical $0.5 \mathrm{~V}$ potential window and decrease the battery-type plateau regions that occur due to phase transformations and thus limit kinetics.

Recent studies have shown good high-rate capability in materials that have not been widely investigated for pseudocapacitive behavior in aqueous electrolytes. A composite of $\mathrm{MoO}_{3}$,
CNTs, and activated carbon (where $\mathrm{MoO}_{3}$ accounted for $10 \%$ of the mass) exhibited a capacitance of $270 \mathrm{~F} \mathrm{~g}^{-1}$ for over 10000 cycles at a 4 minute charge-discharge rate. ${ }^{87}$ The $\mathrm{MoO}_{3}$ mass loading was selected so that the oxide was mostly encapsulated within the carbon matrix in order to prevent degradation during cycling. Tungsten oxide $\left(\mathrm{WO}_{3}\right)$ is interesting for electrochemical capacitors due to its good electronic conductivity when synthesized in a partially reduced form and within a conductive carbon network.$^{88}$ However, the gravimetric capacitance is low ( $\sim 103 \mathrm{~F} \mathrm{~g}^{-1} ; 16 \mathrm{~min}$ ) mostly due to the weight of tungsten.

\section{Non-aqueous electrolyte pseudocapacitor materials}

Some materials exhibit pseudocapacitive behavior in nonaqueous lithium-ion and, occasionally, sodium-ion electrolytes. Materials that exhibit pseudocapacitance do so because ion insertion induces a redox reaction which maintains charge neutrality. They may also have structures that support fast ion insertion. Since the electrolytes are non-aqueous, structural water no longer acts as a beneficial ion-conducting pathway as in aqueous pseudocapacitive materials; rather, it can lead to the degradation of the electrochemical cell. ${ }^{89}$ One advantage for using pseudocapacitive materials in non-aqueous electrolytes is that they typically exhibit capacitance over wider potential ranges than materials in aqueous electrolytes as:

$$
E=\frac{1}{2} C V^{2}
$$

here, $E$ is energy density $\left(\mathrm{J} \mathrm{g}^{-1}\right), C$ is the capacitance $\left(\mathrm{F} \mathrm{g}^{-1}\right)$, and $V$ is the potential range $(\mathrm{V})$. Thus, by widening the potential range from 1 to $4 \mathrm{~V}$, the energy density can increase by nearly an order of magnitude. From a mechanistic standpoint, one is able to separate pseudocapacitance and double-layer capacitance by judiciously selecting electrolytes whose bulky ions will prevent ion insertion. ${ }^{90}$ In the paragraphs below we review materials systems in which ion insertion from non-aqueous electrolytes gives rise to pseudocapacitive charge storage.

\subsection{Amorphous materials}

Amorphous materials exhibit single-phase ion intercalation behavior, and so their charge-discharge behavior may be represented by eqn (2). Some crystalline materials may become amorphous with repeated electrochemical cycling or by the intercalation of ions past a certain composition, as detailed for $\mathrm{V}_{2} \mathrm{O}_{5}$ in the next section. The structural disorder of amorphous materials can be beneficial for EES, ${ }^{91}$ although sometimes these materials will exhibit lower capacities than their crystalline counterparts. Whether amorphous materials are beneficial for pseudocapacitive EES depends upon their high rate capability. Amorphous $\mathrm{MoO}_{3}{ }^{31}$ and $\mathrm{Nb}_{2} \mathrm{O}_{5},{ }^{92}$ for example, exhibit lower capacitances than their crystalline counterparts even at short charging times and in a thin film configuration. These results suggest that the crystalline materials possess better kinetics and/or another charge storage mechanism which leads to higher specific capacitance. On the other hand, amorphous 
$\mathrm{TiO}_{2}$ nanotubes exhibit an interesting transformation to an ordered cubic phase when cycled in a lithium-ion electrolyte. ${ }^{93}$ This material exhibits high rate capability and capacity, and the charge-discharge curves appear like those expected for solidsolution type behavior.

\section{2. $\mathrm{V}_{2} \mathrm{O}_{5}$}

Vanadium oxides form layered structures which are very advantageous for EES. There is a rich structural chemistry associated with these materials due to the large number of oxidation states of vanadium. A recent review describes a number of these materials. ${ }^{94} \mathrm{~V}_{2} \mathrm{O}_{5}$ is very attractive for EES because the high oxidation state of vanadium leads to the possibility of storing more than 1 electron per formula unit $(+5$, $+4,+3$, and +2 are electrochemically accessible) and the ability to form layered compounds. When in the bulk, crystalline (orthorhombic) form (Fig. 15a), $\mathrm{V}_{2} \mathrm{O}_{5}$ does not exhibit capacitive behavior and there are several well-defined voltage plateaus corresponding to different lithiation phases. ${ }^{95}$ Bulk orthorhombic $\mathrm{V}_{2} \mathrm{O}_{5}$ is limited to the storage of one lithium per formula unit before the onset of an irreversible phase transformation. ${ }^{94}$ Lithiation can proceed until the formation of the rock-salt $\omega-\mathrm{Li}_{3} \mathrm{~V}_{2} \mathrm{O}_{5}$ phase at approximately $1.8 \mathrm{~V}$ vs. $\mathrm{Li} / \mathrm{Li}^{+}$. Further lithiation of the bulk crystalline material at lower potentials results in structural degradation. ${ }^{96,97}$

Both amorphous and nanocrystalline forms of $\mathrm{V}_{2} \mathrm{O}_{5}$ can exhibit pseudocapacitive behavior as evidenced by sloping charge-discharge curves during galvanostatic cycling and broad, featureless CVs. One unique class of these materials is synthesized from a $\mathrm{V}_{2} \mathrm{O}_{5}$ gel ${ }^{99}$ into xerogels, ${ }^{100}$ ambigels, ${ }^{101}$ or aerogels ${ }^{90}$ depending on the solvent removal technique. The structure of $\mathrm{V}_{2} \mathrm{O}_{5}$ xerogels (Fig. 15b) consists of $\mathrm{V}_{2} \mathrm{O}_{5}$ bilayers separated from each other by a large van der Waals gap of $\sim 12 \AA$ that contains water molecules in the as-synthesized state. ${ }^{\mathbf{1 0 2}}$ Locally, the structure of the ambigels and aerogels is expected to be similar to the xerogels; the large van der Waals gap is preserved in these materials and its size ranges from 10-14 A depending on the amount of structural water present. This large van der Waals gap allows for the insertion of a large variety of cations. ${ }^{\mathbf{1 0 3 , 1 0 4}}$ The galvanostatic cycling of xerogel and amorphous $\mathrm{V}_{2} \mathrm{O}_{5}$ is shown in Fig. 16 and compared to that of bulk orthorhombic $\mathrm{V}_{2} \mathrm{O}_{5}$.

The pseudocapacitance of high surface area $\mathrm{V}_{2} \mathrm{O}_{5}$ is strongly dependent upon exposure of the active material to the electrolyte.
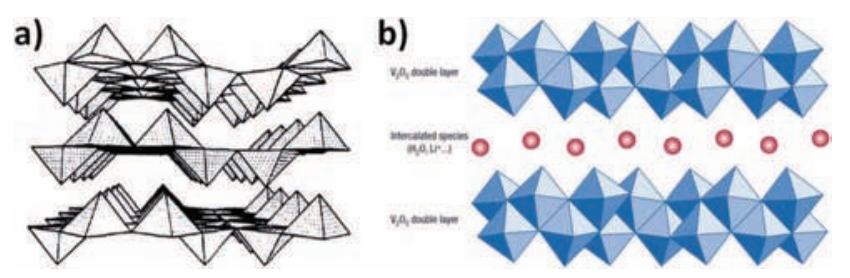

Fig. 15 Two types of layered sheet structures of $\mathrm{V}_{2} \mathrm{O}_{5}$ : (a) the structure of orthorhombic $\mathrm{V}_{2} \mathrm{O}_{5}$ (reproduced from ref. 95 with permission from Elsevier) and (b) the layered structure of $\mathrm{V}_{2} \mathrm{O}_{5}$ xerogels. Reprinted by permission from Macmillan Publishers Ltd: Nat. Mater., ref. 98, copyright 2003.

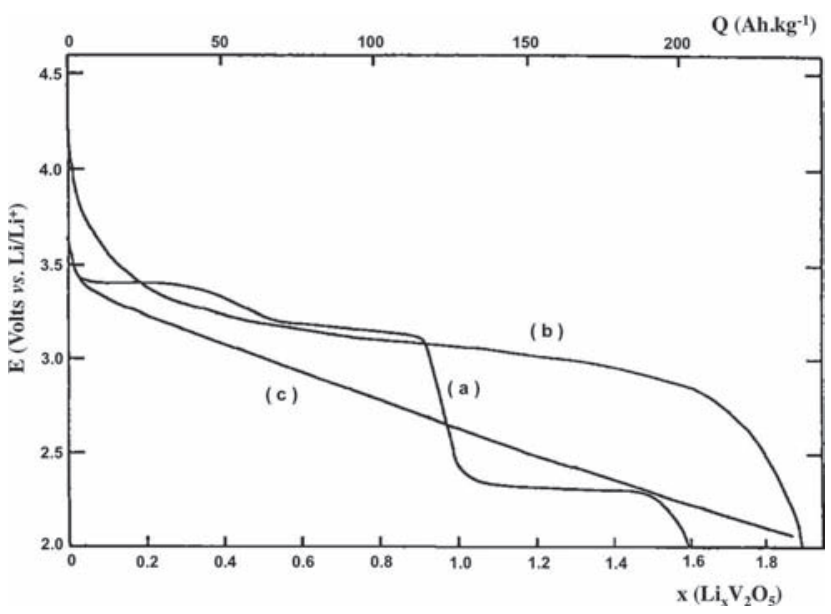

Fig. 16 Galvanostatic cycling of (a) orthorhombic $\mathrm{V}_{2} \mathrm{O}_{5}$, (b) $\mathrm{V}_{2} \mathrm{O}_{5}$ xerogel, and (c) amorphous $\mathrm{V}_{2} \mathrm{O}_{5}$. Reprinted from ref. 105, with permission from Elsevier.

This behavior is one characteristic of an extrinsic pseudocapacitor material. For example, $\mathrm{V}_{2} \mathrm{O}_{5}$ aerogels exhibit almost perfectly capacitive CVs when analyzed using the 'sticky carbon' method in which a small amount of the aerogel (surface area of $280 \mathrm{~m}^{2} \mathrm{~g}^{-1}$ ) material is pressed into a conductive wax (Fig. 17).$^{90}$ In such an electrode architecture, nearly all of the active material surface area can be exposed to the electrolyte. The maximum capacitance of $\mathrm{V}_{2} \mathrm{O}_{5}$ aerogels was determined to be $1300 \mathrm{~F} \mathrm{~g}^{-1}$ $\left(1820 \mathrm{C} \mathrm{g}^{-1} ; 3.9 \mathrm{~h}\right) .{ }^{90}$ On the other hand, an aerogel electrode made using the traditional composite electrode technique exhibits a CV with prominent intercalation peaks. This has been ascribed to the increased crystallization of the aerogel material that occurs during the heat treatment required for fabricating a composite electrode.

Nanocrystalline $\mathrm{V}_{2} \mathrm{O}_{5}$ can also exhibit significant pseudocapacitive behavior. The poor electronic conductivity of $\mathrm{V}_{2} \mathrm{O}_{5}$ must be overcome with the use of an appropriate conductive material

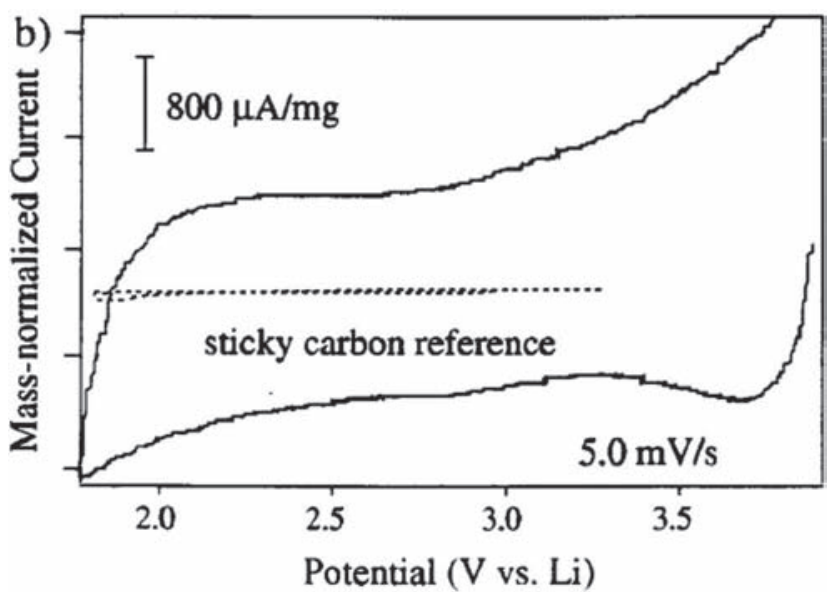

Fig. 17 Cyclic voltammetry of a $\mathrm{V}_{2} \mathrm{O}_{5}$ aerogel electrode at $5 \mathrm{mV} \mathrm{s}^{-1}$ using the sticky carbon electrode. The dotted CV represents the sticky carbon background current. Reproduced with permission from ref. 90. Copyright 2000, The Electrochemical Society. 


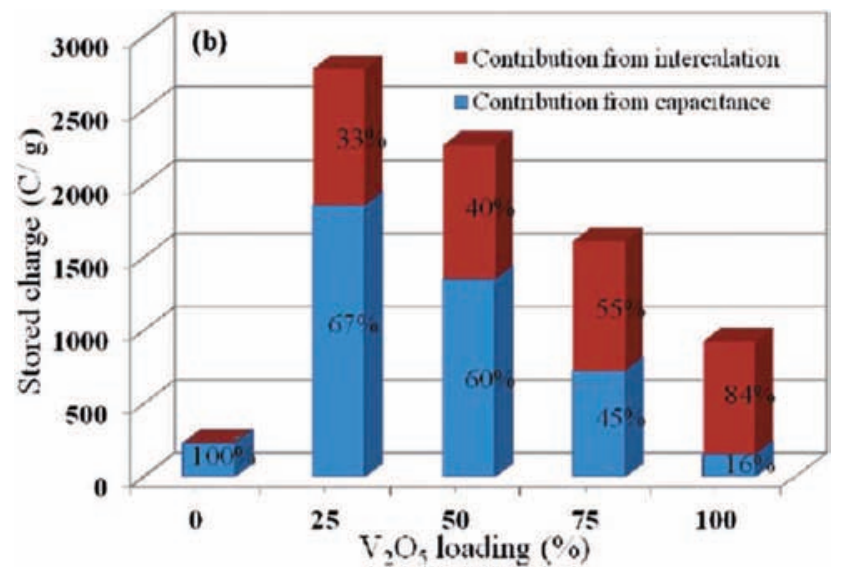

Fig. 18 Total charge storage of $\mathrm{V}_{2} \mathrm{O}_{5}$ (at $0.1 \mathrm{mV} \mathrm{s}^{-1}$ ) chemically deposited onto CNTs, separated into contributions from intercalation (diffusion-controlled current) and capacitance for different $\mathrm{V}_{2} \mathrm{O}_{5}$ thicknesses, represented by different loading \%. Reprinted with permission from ref. 32. Copyright 2011 American Chemical Society.

for fast kinetics. $\mathrm{V}_{2} \mathrm{O}_{5}$ nanowires entangled with CNTs, for example, exhibit capacitive $\mathrm{CVs}$ in sodium-ion non-aqueous electrolyte. ${ }^{106}$ Deposition of $\mathrm{V}_{2} \mathrm{O}_{5}$ layers onto CNTs has been performed using atomic layer deposition (ALD) ${ }^{107}$ electrodeposition, ${ }^{108}$ and hydrolysis. ${ }^{32}$ These studies further demonstrated the importance of exposing as much of the material as possible to the electrolyte for the highest capacitance values. Moreover, the extrinsic pseudocapacitive nature of the $\mathrm{V}_{2} \mathrm{O}_{5}$ was evident as increasing the $\mathrm{V}_{2} \mathrm{O}_{5}$ layer thickness resulted in a

a)
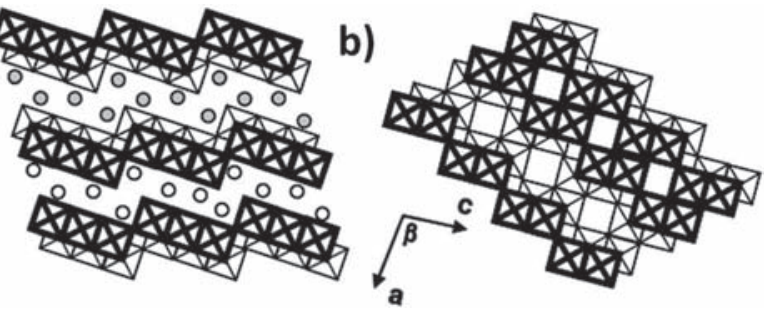

Fig. 19 The structures of (a) $\mathrm{H}_{2} \mathrm{Ti}_{3} \mathrm{O}_{7}$ and (b) $\mathrm{TiO}_{2}(\mathrm{~B})$ as viewed perpendicular to the (010) plane. Reproduced from ref. 112 by permission of IOP Publishing. decrease in the capacitance value, as well as the transition from capacitive to battery-like electrochemical features. This behavior is illustrated in Fig. 18 for $\mathrm{V}_{2} \mathrm{O}_{5}$ that was deposited during an in situ chemical hydrolysis of a vanadium precursor. The separation of diffusion-controlled and capacitive currents was performed using the current-separation technique described by eqn (4).

Nanostructured $\mathrm{V}_{2} \mathrm{O}_{5}$ materials are promising for high-rate EES storage. As an extrinsic pseudocapacitor, exposure of the surface area to the electrolyte is critical. Moreover, increasing the thickness of the material leads to a decrease in the pseudocapacitive behavior. To build high-rate electrodes, the poor electrical conductivity of $\mathrm{V}_{2} \mathrm{O}_{5}$ must be overcome with appropriate conductive supports. In addition, vanadium dissolution is possible and care should be taken to avoid the use of electrolytes that can have even trace amounts of acid as these have been shown to severely limit the life cycle of $\mathrm{V}_{2} \mathrm{O}_{5}$ electrodes. ${ }^{109}$

\section{3. $\quad \mathrm{TiO}_{2}(\mathrm{~B})$ and hydrogen titanates}

Hydrogen titanates, primarily $\mathrm{H}_{2} \mathrm{Ti}_{3} \mathrm{O}_{7}$, and $\mathrm{TiO}_{2}(\mathrm{~B})$ have been investigated for pseudocapacitive EES. In these materials, as in other titanium oxides, charge storage occurs due to the $\mathrm{Ti}+4 /+3$ redox couple, and lithium ion intercalation occurs below $2 \mathrm{~V} v s$. $\mathrm{Li} / \mathrm{Li}^{+}$. The hydrogen titanates are layered structures consisting of edge-sharing $\mathrm{TiO}_{6}$ octahedra separated by protons; heat treatment of these materials leads to dehydration and the formation of the $\mathrm{TiO}_{2}(\mathrm{~B})$ phase, which consists of two edgesharing $\mathrm{TiO}_{6}$ octahedra linked at corners ${ }^{110}$ (as shown in Fig. 19). The resulting $\mathrm{TiO}_{2}$ material has a lower density ${ }^{111}$ and therefore a more open structure than anatase or rutile phases of $\mathrm{TiO}_{2}$, which makes it interesting for pseudocapacitive energy storage.

Investigations of the electrochemical behavior of hydrogen titanates in lithium ion non-aqueous electrolytes have shown that the charge storage is pseudocapacitive in nature. These investigations have been primarily carried out on nanostructured materials such as nanowires and nanotubes. ${ }^{113-117}$ The materials exhibit the electrochemical features of pseudocapacitance, as shown in Fig. 20 for $\mathrm{H}_{2} \mathrm{Ti}_{3} \mathrm{O}_{7}$ nanowires. A reversible capacity of $597 \mathrm{C} \mathrm{g}^{-1}\left(\sim 398 \mathrm{~F} \mathrm{~g}^{-1}\right.$; $\left.\sim 5 \mathrm{~min}\right)$ has been obtained with a composite electrode composed of hydrogen
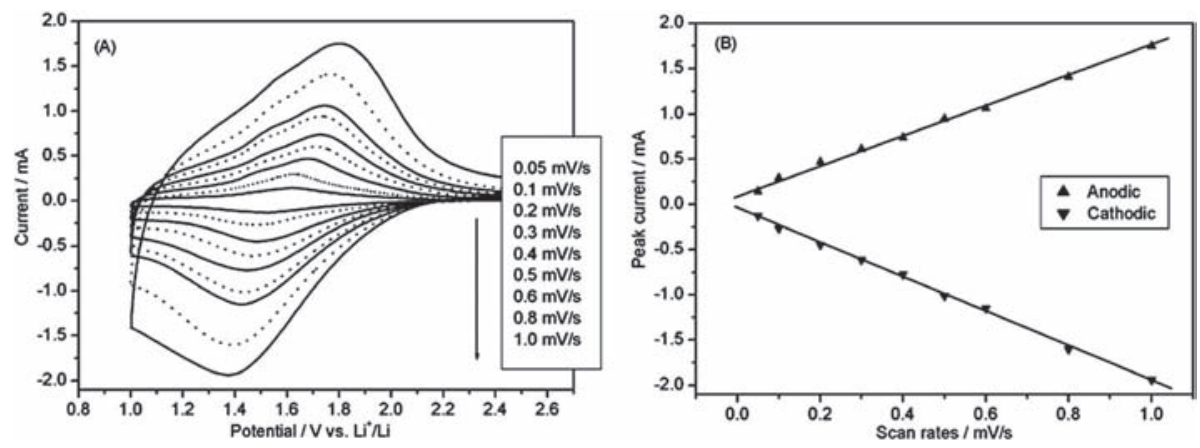

Fig. 20 (a) $\mathrm{CV}_{\mathrm{s}}$ of $\mathrm{H}_{2} \mathrm{Ti}_{3} \mathrm{O}_{7}$ nanowires in a non-aqueous lithium ion electrolyte; (b) the dependence of the peak current with sweep rate is linear indicating a surface-controlled, capacitive response. Reprinted with permission from ref. 113. Copyright 2005 American Chemical Society. 
titanate nanotubes in which the active material mass loading was $3-4 \mathrm{mg} \mathrm{cm}^{-2} \cdot{ }^{114}$ The pseudocapacitive behavior of hydrogen titanates has been attributed to the increased surface area of the nanostructured materials as well as the large interlayer spacing of the titanates, $\sim 8 \AA$. $^{113}$

The electrochemical behavior of $\mathrm{TiO}_{2}(\mathrm{~B})$ is also pseudocapacitive in nature, as first reported by Zukalová, et al. ${ }^{111}$ Charge storage in $\mathrm{TiO}_{2}$ (B) occurs via the intercalation of lithium ions in a non-aqueous electrolyte:

$$
\mathrm{TiO}_{2}(\mathrm{~B})+x \mathrm{Li}^{+}+x \mathrm{e}^{-} \leftrightarrow \mathrm{Li}_{x} \mathrm{TiO}_{2}(\mathrm{~B})
$$

It is understood that some lithium remains in the material after the first cycle so that $\mathrm{TiO}_{2}(\mathrm{~B})$ is not recovered. ${ }^{118}$ The theoretical capacity for a full 1 electron redox reaction is $335 \mathrm{~mA}$ $\mathrm{h} \mathrm{g}^{-1}\left(1206 \mathrm{C} \mathrm{g}^{-1}\right)$. In a CV, $\mathrm{TiO}_{2}(\mathrm{~B})$ exhibits two sets of cathodic redox peaks, at $\sim 1.5$ and $1.6 \mathrm{~V}$, which are located at lower potentials than for lithium ion intercalation into anatase $\mathrm{TiO}_{2}$

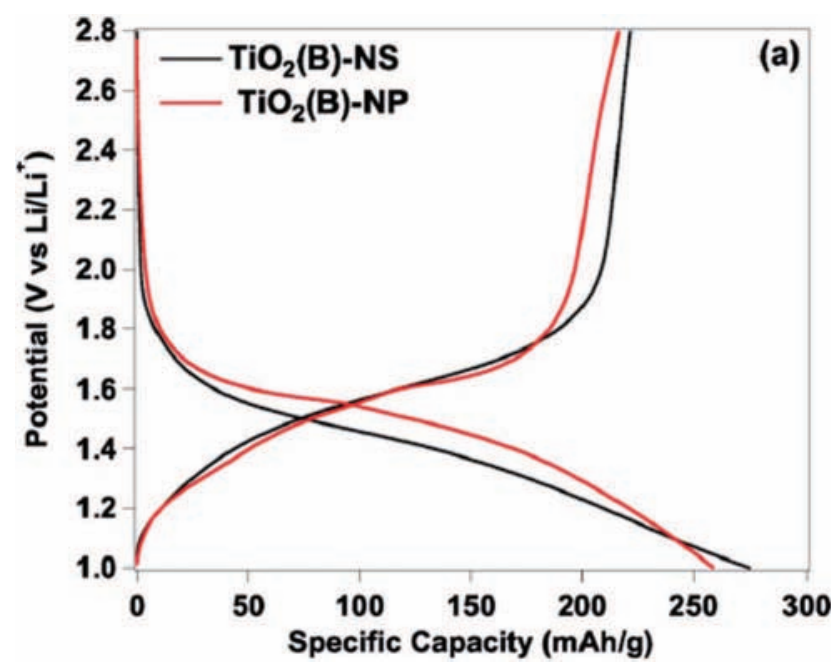

Fig. 21 Galvanostatic charge-discharge plots of $\mathrm{TiO}_{2}(\mathrm{~B})$ nanosheets (NS) and nanoparticles (NP) at current density of $25 \mathrm{~mA} \mathrm{~g}^{-1}$. Reprinted with permission from ref. 119. Copyright 2012 American Chemical Society. $(\sim 1.75 \mathrm{~V})$. In bulk $\mathrm{TiO}_{2}(\mathrm{~B})$, these peaks exhibit a linear dependence on the sweep rate indicative of a pseudocapacitive process. ${ }^{111}$ The material may also be synthesized in nanosheet and nanowire forms, and their electrochemical behavior is slightly different; ${ }^{119}$ in both cases, however, the chargedischarge profiles are sloping as shown in Fig. 21. The pseudocapacitive behavior of $\mathrm{TiO}_{2}(\mathrm{~B})$, which is different from other forms of $\mathrm{TiO}_{2}$, has been ascribed to the low-density crystal structure that contains channels for rapid lithium ion transport from the surface to the sub-surface. ${ }^{111}$ Nanostructuring, in the form of nanowires, nanosheets, and nanoparticles, decreases the ion diffusion distance and thus increases the rate capability even further. ${ }^{118}$ For example, $\mathrm{TiO}_{2}(\mathrm{~B})$ nanosheets exhibit capacities of $777 \mathrm{C} \mathrm{g}^{-1}\left(518 \mathrm{~F} \mathrm{~g}^{-1}\right)$ in $\sim 3.9 \mathrm{~min}^{.120}$

The hydrogen titanates and $\mathrm{TiO}_{2}(\mathrm{~B})$ are examples of intrinsic pseudocapacitors. They exhibit broad, overlapping redox peaks in CVs and continuously sloping charge-discharge curves, even in bulk form. Further studies are needed to fully characterize the rate-capability of these materials, particularly at timescales of 1 minute or less. Unlike in $\mathrm{V}_{2} \mathrm{O}_{5}$, exposure of the surface to the electrolyte is not critical as thick composite electrodes exhibit pseudocapacitive behavior. A major concern with these materials is that nanostructured forms, which show higher capacity and rate capability than the bulk, exhibit irreversible capacity loss during cycling.

\section{4. $\mathrm{T}-\mathrm{Nb}_{2} \mathrm{O}_{5}$}

While the electrochemical energy storage capabilities of $\mathrm{Nb}_{2} \mathrm{O}_{5}$ have been known since $1980,{ }^{121,122}$ only recently has the pseudocapacitive behavior of orthorhombic $\mathrm{T}-\mathrm{Nb}_{2} \mathrm{O}_{5}$ been identi-

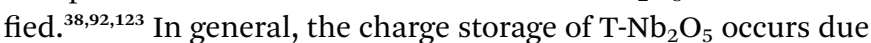
to the insertion of lithium ions in non-aqueous electrolytes at a potential of $<2 \mathrm{~V} v s$. $\mathrm{Li}^{2} / \mathrm{Li}^{+}$. Based on the redox of the $\mathrm{Nb}+5 /+4$ couple, charge storage occurs up to $2 \mathrm{Li}^{+} / \mathrm{Nb}_{2} \mathrm{O}_{5}$ for a maximum capacity of $720 \mathrm{C} \mathrm{g}^{-1} \cdot{ }^{124}$ The pseudocapacitive behavior is highly dependent upon the presence of a crystalline structure. Amorphous $\mathrm{Nb}_{2} \mathrm{O}_{5}$ exhibits lower specific capacitance values $(262 \mathrm{~F}$ $\left.\mathrm{g}^{-1} ; 314 \mathrm{C} \mathrm{g}^{-1} ; 4 \mathrm{~min}\right)$ than $\mathrm{T}-\mathrm{Nb}_{2} \mathrm{O}_{5}\left(555 \mathrm{~F} \mathrm{~g}^{-1} ; 666 \mathrm{C} \mathrm{g}^{-1} ; 4\right.$ min) despite the fact that the amorphous material has a much
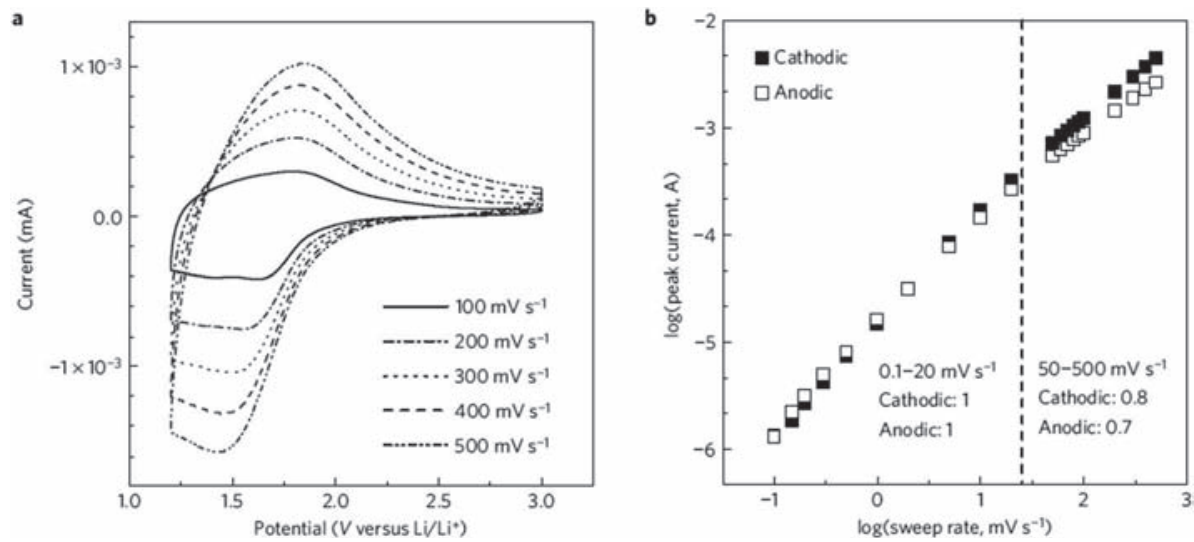

Fig. 22 (a) $\mathrm{CVs}$ of $\mathrm{T}-\mathrm{Nb}_{2} \mathrm{O}_{5}$ from $100-500 \mathrm{mV} \mathrm{s}{ }^{-1}$ exhibit broad, highly reversible redox peaks. (b) The peak cathodic and anodic currents scale linearly with the sweep rate up to $50 \mathrm{mV} \mathrm{s}^{-1}$; beyond this rate, diffusion begins to limit the rate capability. ${ }^{38}$ 
higher surface area. ${ }^{123}$ The structure of $\mathrm{T}-\mathrm{Nb}_{2} \mathrm{O}_{5}$ consists of sheets of corner- or edge-sharing $\mathrm{Nb}^{+5}$ polyhedra along the (001) plane that are coordinated by 6 or $7 \mathrm{O}^{2-}$. Computations indicate that the (001) plane exhibits low energy barriers for lithium ion transport and gives rise to the pseudocapacitive behavior observed in the material. ${ }^{125,126}$

The $\mathrm{T}-\mathrm{Nb}_{2} \mathrm{O}_{5}$ material exhibits the features representative of pseudocapacitive charge storage for sweep rates up to $50-60 \mathrm{mV}$ $\mathrm{s}^{-1}$ which corresponds to 1 minute charge-discharge times. The CVs (Fig. 22a) exhibit broad redox peaks below $2 \mathrm{~V}$ and the galvanostatic charge-discharge characteristic is almost linear. The peak current scales linearly with sweep rate over a broad range of sweep rates as shown in Fig. 22b. Therefore, along with $\mathrm{TiO}_{2}(\mathrm{~B})$ and the hydrogen titanates, $\mathrm{T}-\mathrm{Nb}_{2} \mathrm{O}_{5}$ can be identified as a material that exhibits intrinsic intercalation pseudocapacitance in non-aqueous electrolytes. These types of intrinsic pseudocapacitors do not need high-surface areas as do those based on $\mathrm{V}_{2} \mathrm{O}_{5}$, for example. Since exposure of the surface of $\mathrm{T}-\mathrm{Nb}_{2} \mathrm{O}_{5}$ to the electrolyte is not critical for high rate behavior, such pseudocapacitive materials should be beneficial for practical devices as traditional composite electrode architectures may be utilized.

\subsection{High-rate performance of non-aqueous electrolyte pseudocapacitive materials}

As in aqueous electrolytes, the pseudocapacitive behavior of non-aqueous electrolytes should be examined at fast chargedischarge times, on the order of 1 minute. As there are fewer materials overall that exhibit pseudocapacitance in nonaqueous electrolytes, there are also fewer studies of the highrate capability.

Since $\mathrm{V}_{2} \mathrm{O}_{5}$ is an extrinsic pseudocapacitor material, only nanostructured forms have been considered for pseudocapacitor applications. Over a typical $\mathrm{V}_{2} \mathrm{O}_{5}$ potential window of $2.5 \mathrm{~V}$, cyclic voltammetry sweep rates between 20 and $50 \mathrm{mV} \mathrm{s}^{-1}$ are the most relevant for high-rate application. Even with nanostructuring, composite electrodes with high mass loadings of $\mathrm{V}_{2} \mathrm{O}_{5}$ exhibit low capacity at high rates. $\mathrm{V}_{2} \mathrm{O}_{5}$ nanowires intertwined with carbon nanotubes mixed in a traditional slurry electrode exhibit a capacitance of $95 \mathrm{~F} \mathrm{~g}^{-1}\left(225 \mathrm{C} \mathrm{g}^{-1}\right)$ at a charge-discharge time of 2 minutes with a $\mathrm{V}_{2} \mathrm{O}_{5}$ mass loading of 4-5 $\mathrm{mg} \mathrm{cm}^{-2} \cdot{ }^{127}$ In a sodium-ion electrolyte, $\mathrm{V}_{2} \mathrm{O}_{5} /$ carbon nanotube composites with a mass loading of $1-3 \mathrm{mg} \mathrm{cm}^{-2}$ store $96 \mathrm{~F} \mathrm{~g}^{-1}\left(240 \mathrm{C} \mathrm{g}^{-1}\right)$ in 50 seconds. ${ }^{106}$ Much higher values are obtained with lower $\mathrm{V}_{2} \mathrm{O}_{5}$ mass loading, as in the case of electrochemically deposited $\mathrm{V}_{2} \mathrm{O}_{5}$ on carbon nanotubes. ${ }^{108}$ For a $\mathrm{V}_{2} \mathrm{O}_{5}$ mass loading of $8.9 \mathrm{wt} \%\left(25 \mu \mathrm{g} \mathrm{cm}{ }^{-2}\right)$, the capacitance was $1000 \mathrm{~F} \mathrm{~g}^{-1}\left(2500 \mathrm{C} \mathrm{g}^{-1}\right)$ for a charge-discharge time of 50 seconds. As the $\mathrm{V}_{2} \mathrm{O}_{5}$ mass loading increased to $51.3 \mathrm{wt} \%$ (305 $\mu \mathrm{g} \mathrm{cm}^{-2}$ ), the capacitance decreased significantly to $150 \mathrm{~F}$ $\mathrm{g}^{-1}\left(375 \mathrm{C} \mathrm{g}^{-1}\right)$ for the same charge-discharge rate.

$\mathrm{TiO}_{2}(\mathrm{~B})$ and $\mathrm{H}_{2} \mathrm{Ti}_{3} \mathrm{O}_{7}$ exhibit intrinsic pseudocapacitive behavior and most studies of these materials have utilized traditional slurry composite electrodes. Hydrogen titanate nanowire electrodes, with an active material mass loading of 2-3 $\mathrm{mg} \mathrm{cm}^{-2}$ exhibit a capacitance of $317 \mathrm{~F} \mathrm{~g}^{-1}\left(476 \mathrm{C} \mathrm{g}^{-1}\right)$ at a charge-discharge time of 3 minutes. ${ }^{113} \mathrm{TiO}_{2}(\mathrm{~B})$ nanowires, also measured utilizing a traditional slurry electrode, give rise to capacitances of $204 \mathrm{~F} \mathrm{~g}^{-1}\left(306 \mathrm{C} \mathrm{g}^{-1}\right)$ at a charge-discharge time of 1.7 minutes. ${ }^{128}$

Recent work on the lithium-ion storage properties of anatase $\mathrm{TiO}_{2}$ nanosheets has shown that such materials exhibit significant broadening of the $\mathrm{Li}^{+}$intercalation peaks and sloping charge-discharge profiles. ${ }^{129,130}$ Studies of the kinetics of the nanosheet electrodes showed that most of the charge storage in these materials is pseudocapacitive in origin. ${ }^{131}$ Thick composite electrodes of $\mathrm{TiO}_{2}$ nanosheets exhibited very good rate capability with $428 \mathrm{C} \mathrm{g}^{-1}\left(\sim 214 \mathrm{~F} \mathrm{~g}^{-1}\right)$ stored in 2 minutes at an active mass loading of $1.5-1.7 \mathrm{mg} \mathrm{cm}^{-2}$. These studies indicate that the synthesis of lithium-ion intercalation compounds in nanosheet form may be a convenient route for producing extrinsic, non-aqueous pseudocapacitive materials.

Although there are few studies on the pseudocapacitive behavior of $\mathrm{Nb}_{2} \mathrm{O}_{5}$, recent results suggest that it is a promising material in lithium-ion non-aqueous electrolytes. At a timescale of 1 minute and utilizing a composite electrode with an active material mass loading of $1-1.5 \mathrm{mg} \mathrm{cm}^{-2}$, the capacitance was $333 \mathrm{~F} \mathrm{~g}^{-1}\left(400 \mathrm{C} \mathrm{g}^{-1}\right){ }^{38}$ This value represents $67 \%$ of the theoretical capacitance for the storage of lithium in $\mathrm{Nb}_{2} \mathrm{O}_{5}$ and compares well with results obtained using low mass loading which were $\sim 75 \%$ of the theoretical capacitance. ${ }^{123}$ This comparison underscores another benefit of intrinsic pseudocapacitors in that there is much less of a decrease in specific capacitance when the materials are incorporated in composite electrodes.

\section{Summary and future outlook}

Pseudocapacitive transition metal oxides offer the tantalizing combination of high rate and high energy density EES. These materials have the potential to overcome the low energy density limitations of electrochemical capacitors. From an analytical standpoint, pseudocapacitance is defined whenever the potential depends upon the state of charge. Pseudocapacitive behavior manifests itself in several electrochemical features that are easily identifiable in a CV, a galvanostatic chargedischarge plot, or with AC impedance. Some materials are intrinsic pseudocapacitors, where the pseudocapacitive behavior is apparent with low surface areas and composite electrode architectures: these include $\mathrm{RuO}_{2} \cdot 0.5 \mathrm{H}_{2} \mathrm{O}, \mathrm{MnO}_{2}$, $\mathrm{TiO}_{2}(\mathrm{~B})$, and $\mathrm{Nb}_{2} \mathrm{O}_{5}$. Other materials are extrinsic pseudocapacitors, where the pseudocapacitive behavior is apparent only with very high surface areas and sophisticated electrode architectures whose function it is to expose as much of the material's surface to the electrolyte as possible. Typically, these extrinsic pseudocapacitor materials are traditional battery materials in their bulk state, such as $\mathrm{Ni}(\mathrm{OH})_{2}$ and $\mathrm{V}_{2} \mathrm{O}_{5}$. With such materials, it is particularly important to demonstrate pseudocapacitive electrochemical features beyond just a high capacitance at a short timescale.

If pseudocapacitor materials are to move forward towards device applications, there are two significant issues which need to be addressed. One need is to have a consistent set of material/ electrode metrics which are relevant for devices. As mentioned 
previously, it can be misleading to consider a material to be a high energy density pseudocapacitor when low weight loadings or thin films are used and charge-discharge experiments are carried out over tens of minutes. Some of the parameters discussed in this review provide the basis for pseudocapacitor metrics: the need to demonstrate charge-discharge behavior of 1 minute or less, with capacitances higher than $300 \mathrm{~F} \mathrm{~g}^{-1}$ and with active material mass loading of $>1 \mathrm{mg} \mathrm{cm}^{-2}$. These conditions emphasize the point that the electrochemical behavior of materials considered as pseudocapacitive should be examined at experimental timescales on the order of minutes and seconds. This is critical as lithium-ion battery materials are now routinely characterized at $10 \mathrm{C}$ rates, or 6 minute chargedischarge. This review shows that several pseudocapacitive materials meet these criteria or are very close.

The second significant issue is to define devices which incorporate pseudocapacitive materials. There are few reports of devices utilizing two pseudocapacitive transition metal oxides at both electrodes. This is due to the difficulty in finding suitable pseudocapacitive material pairs to give high device voltage and good rate capability. In aqueous electrolytes, $\mathrm{MnO}_{2} / / \mathrm{MnO}_{2}$ and $\mathrm{MnO}_{2} / / \mathrm{Fe}_{3} \mathrm{O}_{4}$ devices have been investigated. ${ }^{9}$ In these cases, the energy density was less than $10 \mathrm{~W} \mathrm{~h} \mathrm{~kg}^{-1}$. The problem of finding suitable pseudocapacitor cathode materials seems particularly difficult with non-aqueous electrolytes. As a result, most research has focused on fabricating asymmetric devices where the pseudocapacitive electrode is paired with a high surface area activated carbon. A closely related issue which impacts devices directly is the nature of the electrode architecture. In order to fabricate practical devices, the material loading per footprint area needs to be $>1 \mathrm{mg} \mathrm{cm}^{-2}$ and while several traditional electrode structures have been useful in cases with intrinsic pseudocapacitors, this topic is clearly one of considerable importance. Transitioning pseudocapacitive materials from three-electrode, low mass loading experiments towards two-electrode cells with high mass loading that retain high rate capability is a critical step which will enable EES to achieve a goal of having both high energy and high power densities in the same material.

\section{Acknowledgements}

This work was supported as part of the Molecularly Engineered Energy Materials, an Energy Frontier Research Center funded by the U.S. Department of Energy, Office of Science, Office of Basic Energy Sciences, under award DE-SC001342. P.S. acknowledges the support from the European Research Council (ERC, Advanced Grant, ERC-2011-AdG, Project no. 291543 - IONACES) and the Chair of Excellence "Embedded multi-functionnal nanomaterials" from the EADS Foundation.

\section{References}

1 J. R. Miller and A. F. Burke, Electrochem. Soc. Interface, 2008, 53-57.

2 P. V. Braun, J. Cho, J. H. Pikul, W. P. King and H. Zhang, Curr. Opin. Solid State Mater. Sci., 2012, 16, 186-198.
3 J. R. Miller and P. Simon, Science, 2008, 321, 651-652.

4 R. Kötz, Electrochim. Acta, 2000, 45, 2483-2498.

5 R. Huggins, Solid State Ionics, 2000, 134, 179-195.

6 B. Dunn, H. Kamath and J.-M. Tarascon, Science, 2011, 334, 928-935.

7 B. E. Conway, Electrochemical Supercapacitors: Scientific Fundamentals and Technological Applications, KluwerAcademic, 1999.

8 US Pat., 2,800,616, 1957.

9 J. W. Long, D. Bélanger, T. Brousse, W. Sugimoto, M. B. Sassin and O. Crosnier, MRS Bull., 2011, 36, 513-522.

10 R. Signorelli, D. C. Ku, J. G. Kassakian and J. E. Schindall, Proc. IEEE, 2009, 97, 1837-1847.

11 P. Simon and A. Burke, Electrochem. Soc. Interface, 2008, 3843.

12 L. L. Zhang and X. S. Zhao, Chem. Soc. Rev., 2009, 38, 25202531.

13 C. Merlet, B. Rotenberg, P. A. Madden, P.-L. Taberna, P. Simon, Y. Gogotsi and M. Salanne, Nat. Mater., 2012, 11, 306-310.

14 P. Simon and Y. Gogotsi, Nat. Mater., 2008, 7, 845-854.

15 L. Hao, X. Li and L. Zhi, Adv. Mater., 2013, 25, 3899-3904.

16 J. Chmiola, G. Yushin, Y. Gogotsi, C. Portet, P. Simon and P. L. Taberna, Science, 2006, 313, 1760-1763.

17 K. Fic, E. Frackowiak and F. Béguin, J. Mater. Chem., 2012, 22, 24213-24223.

18 R. Lin, P.-L. Taberna, S. Fantini, V. Presser, C. R. Perez, F. Malbosc, N. L. Rupesinghe, K. B. K. Teo, Y. Gogotsi and P. Simon, J. Phys. Chem. Lett., 2011, 2, 2396-2401.

19 Y. Huang, J. Liang and Y. Chen, Small, 2012, 8, 1805-1834. 20 W.-Y. Tsai, R. Lin, S. Murali, L. L. Zhang, J. K. McDonough, R. S. Ruoff, P.-L. Taberna, Y. Gogotsi and P. Simon, Nano Energy, 2013, 2, 403-411.

21 Y. Gogotsi and P. Simon, Science, 2011, 334, 917-918.

22 S. Trasatti and G. Buzzanca, J. Electroanal. Chem. Interfacial Electrochem., 1971, 29, 1-5.

23 J. P. Zheng, P. J. Cygan and T. R. Jow, J. Electrochem. Soc., 1995, 142, 2699-2703.

24 J. W. Long, K. E. Swider, C. I. Merzbacher and D. R. Rolison, Langmuir, 1999, 15, 780-785.

25 W. Dmowski, T. Egami, K. E. Swider-Lyons, C. T. Love and D. R. Rolison, J. Phys. Chem. B, 2002, 106, 12677-12683.

26 E. Herrero, L. J. Buller and H. D. Abruña, Chem. Rev., 2001, 101, 1897-1930.

27 B. E. Conway, Electrochim. Acta, 1993, 38, 1249-1258.

28 T.-C. Liu, W. G. Pell, B. E. Conway and S. L. Roberson, J. Electrochem. Soc., 1998, 145, 1882-1888.

29 J. Wang, J. Polleux, J. Lim and B. Dunn, J. Phys. Chem. C, 2007, 111, 14925-14931.

30 T. Brezesinski, J. Wang, J. Polleux, B. Dunn and S. H. Tolbert, J. Am. Chem. Soc., 2009, 131, 1802-1809.

31 T. Brezesinski, J. Wang, S. H. Tolbert and B. Dunn, Nat. Mater., 2010, 9, 146-151.

32 M. Sathiya, A. S. Prakash, K. Ramesha, J.-M. Tarascon and A. K. Shukla, J. Am. Chem. Soc., 2011, 133, 16291-16299.

33 W. Yan, J. Y. Kim, W. Xing, K. C. Donavan, T. Ayvazian and R. M. Penner, Chem. Mater., 2012, 24, 2382-2390. 
34 S. Ardizzone, G. Fregonara and S. Trasatti, Electrochim. Acta, 1989, 35, 263-267.

35 D. Baronetto, N. Krstajic and S. Trasatti, Electrochim. Acta, 1994, 39, 2359-2362.

36 B. E. Conway, J. Electrochem. Soc., 1991, 138, 1539-1548.

37 A. J. Bard and L. R. Faulkner, Electrochemical Methods: Fundamentals and Applications, John Wiley \& Sons, Inc., New York, 2001.

38 V. Augustyn, J. Come, M. A. Lowe, J. W. Kim, P.-L. Taberna, S. H. Tolbert, H. D. Abruña, P. Simon and B. Dunn, Nat. Mater., 2013, 12, 518-522.

39 R. H. Nilson, M. T. Brumbach and B. C. Bunker, J. Electrochem. Soc., 2011, 158, A678-A688.

40 T. Brezesinski, J. Wang, R. Senter, K. Brezesinski, B. Dunn and S. H. Tolbert, ACS Nano, 2010, 4, 967-977.

41 W. Sugimoto, H. Iwata, K. Yokoshima, Y. Murakami and Y. Takasu, J. Phys. Chem. B, 2005, 109, 7330-7338.

42 T. Brousse, M. Toupin, R. Dugas, L. Athouël, O. Crosnier and D. Bélanger, J. Electrochem. Soc., 2006, 153, A2171A2180.

43 M. Okubo, E. Hosono, J. Kim, M. Enomoto, N. Kojima, T. Kudo, H. Zhou and I. Honma, J. Am. Chem. Soc., 2007, 129, 7444-7452.

44 M. M. Thackeray, Prog. Solid State Chem., 1997, 25, 1-71.

45 T. Ohzuku, A. Ueda and N. Yamamota, J. Electrochem. Soc., 1995, 142, 1431-1435.

46 Z. Choi, D. Kramer and R. Mönig, J. Power Sources, 2013, 240, 245-251.

47 K. Naoi, S. Ishimoto, Y. Isobe and S. Aoyagi, J. Power Sources, 2010, 195, 6250-6254.

48 H. Y. Lee and J. B. Goodenough, J. Solid State Chem., 1999, 144, 220-223.

49 M. Toupin, T. Brousse and D. Bélanger, Chem. Mater., 2004, 16, 3184-3190.

50 O. Ghodbane, J.-L. Pascal and F. Favier, ACS Appl. Mater. Interfaces, 2009, 1, 1130-1139.

51 W. Wei, X. Cui, W. Chen and D. G. Ivey, Chem. Soc. Rev., 2011, 40, 1697-1721.

52 P. Ragupathy, H. N. Vasan and N. Munichandraiah, J. Electrochem. Soc., 2008, 155, A34-A40.

53 S. Devaraj and N. Munichandraiah, J. Phys. Chem. C, 2008, 112, 4406-4417.

54 B. Djurfors, J. N. Broughton, M. J. Brett and D. G. Ivey, Acta Mater., 2005, 53, 957-965.

55 Y.-C. Hsieh, K.-T. Lee, Y.-P. Lin, N.-L. Wu and S. W. Donne, J. Power Sources, 2008, 177, 660-664.

56 T. Brousse, P.-L. Taberna, O. Crosnier, R. Dugas, P. Guillemet, Y. Scudeller, Y. Zhou, F. Favier, D. Bélanger and P. Simon, J. Power Sources, 2007, 173, 633-641.

57 C.-C. Hu, W.-C. Chen and K.-H. Chang, J. Electrochem. Soc., 2004, 151, A281-A290.

58 J. W. Lee, A. S. Hall, J. Kim and T. E. Mallouk, Chem. Mater., 2012, 24, 1158-1164.

59 S.-Y. Wang, K.-C. Ho, S.-L. Kuo and N.-L. Wu, J. Electrochem. Soc., 2006, 153, A75-A80.

60 X.-H. Xia, J.-P. Tu, X.-L. Wang, C.-D. Gu and X.-B. Zhao, Chem. Commun., 2011, 47, 5786-5788.
61 S. Kuo and N. Wu, J. Power Sources, 2006, 162, 1437-1443.

62 L. Yu, G. Zhang, C. Yuan and X. W. D. Lou, Chem. Commun., 2013, 49, 137-139.

63 D. P. Dubal, D. S. Dhawale, R. R. Salunkhe, S. M. Pawar and C. D. Lokhande, Appl. Surf. Sci., 2010, 256, 4411-4416.

64 M. P. Yeager, W. Du, Q. Wang, N. A. Deskins, M. Sullivan, B. Bishop, D. Su, W. Xu, S. D. Senanayake, R. Si, J. Hanson and X. Teng, ChemSusChem, 2013, 6, 1983-1992.

65 G. An, P. Yu, M. Xiao, Z. Liu, Z. Miao, K. Ding and L. Mao, Nanotechnology, 2008, 19, 275709.

66 S.-L. Kuo and N.-L. Wu, Electrochem. Solid-State Lett., 2005, 8, A495-A499.

67 C. Yuan, J. Li, L. Hou, J. Lin, G. Pang, L. Zhang, L. Lian and X. Zhang, RSC Adv., 2013, 3, 18573-18578.

68 N. Padmanathan and S. Selladurai, Ionics, 2013, DOI: 10.1007/s11581-013-1009-8.

69 S. K. Meher and G. R. Rao, J. Phys. Chem. C, 2011, 115, 25543-25556.

70 J. Du, G. Zhou, H. Zhang, C. Cheng, J. Ma, W. Wei, L. Chen and T. Wang, ACS Appl. Mater. Interfaces, 2013, 5, 74057409.

71 T.-Y. Wei, C.-H. Chen, H.-C. Chien, S.-Y. Lu and C.-C. Hu, Adv. Mater., 2010, 22, 347-351.

72 A. Van der Ven, D. Morgan, Y. S. Meng and G. Ceder, J. Electrochem. Soc., 2006, 153, A210-A215.

73 F. Zhou, X. Zhao, A. van Bommel, A. W. Rowe and J. R. Dahn, Chem. Mater., 2010, 22, 1015-1021.

74 X. Liu, R. Ma, Y. Bando and T. Sasaki, Adv. Mater., 2012, 24, 2148-2153.

75 F. Beck and P. Ruetschi, Electrochim. Acta, 2000, 45, 24672482.

76 W. Xing, S. Qiao, X. Wu, X. Gao, J. Zhou, S. Zhuo, S. B. Hartono and D. Hulicova-Jurcakova, J. Power Sources, 2011, 196, 4123-4127.

77 V. Srinivasan, J. W. Weidner and J. Newman, J. Electrochem. Soc., 2001, 148, A969.

78 H. Jiang, T. Zhao, C. Li and J. Ma, J. Mater. Chem., 2011, 21, 3818.

79 C. Zhao, X. Wang, S. Wang, H. Wang, Y. Yang and W. Zheng, Mater. Res. Bull., 2013, 48, 3189-3195.

80 W.-J. Zhou, M.-W. Xu, D.-D. Zhao, C.-L. Xu and H.-L. Li, Microporous Mesoporous Mater., 2009, 117, 55-60.

81 M. Toupin, T. Brousse and D. Bélanger, Chem. Mater., 2002, 14, 3946-3952.

82 S. Chou, J. Wang, S. Chew, H. Liu and S. Dou, Electrochem. Commun., 2008, 10, 1724-1727.

83 Z. Fan, J. Chen, B. Zhang, F. Sun, B. Liu and Y. Kuang, Mater. Res. Bull., 2008, 43, 2085-2091.

84 J. Yan, Z. Fan, T. Wei, W. Qian, M. Zhang and F. Wei, Carbon, 2010, 48, 3825-3833.

85 A. E. Fischer, K. A. Pettigrew, D. R. Rolison, R. M. Stroud and J. W. Long, Nano Lett., 2007, 7, 281-286.

86 H. B. Li, M. H. Yu, F. X. Wang, P. Liu, Y. Liang, J. Xiao, C. X. Wang, Y. X. Tong and G. W. Yang, Nat. Commun., 2013, 4, 1894.

87 S. Okashy, M. Noked, T. Zimrin and D. Aurbach, J. Electrochem. Soc., 2013, 160, A1489-A1496. 
88 C. Sassoye, C. Laberty, H. Le Khanh, S. Cassaignon, C. Boissière, M. Antonietti and C. Sanchez, Adv. Funct. Mater., 2009, 19, 1922-1929.

89 Y. Wang, H. Shang, T. Chou and G. Cao, J. Phys. Chem. B, 2005, 109, 11361-11366.

90 W. Dong, D. R. Rolison and B. Dunn, Electrochem. SolidState Lett., 2000, 3, 457-459.

91 J. C. Lytle, C. P. Rhodes, J. W. Long, K. a. Pettigrew, R. M. Stroud and D. R. Rolison, J. Mater.Chem., 2007, 17, 1292.

92 K. Brezesinski, J. Wang, J. Haetge, C. Reitz, S. O. Steinmueller, S. H. Tolbert, B. M. Smarsly, B. Dunn and T. Brezesinski, J. Am. Chem. Soc., 2010, 132, 6982-6990.

93 H. Xiong, H. Yildirim, E. V. Shevchenko, V. B. Prakapenka, B. Koo, M. D. Slater, M. Balasubramanian, S. K. R. S. Sankaranarayanan, P. Greeley, S. Tepavcevic, N. M. Dimitrijevic, P. Podsiadlo, C. S. Johnson and T. Rajh, J. Phys. Chem. C, 2012, 116, 3181-3187.

94 N. A. Chernova, M. Roppolo, A. C. Dillon and M. S. Whittingham, J. Mater. Chem., 2009, 19, 2526-2552.

95 C. Delmas, H. Cognac-Auradou, J. Cocciantelli, M. Ménétrier and J. Doumerc, Solid State Ionics, 1994, 69, 257-264.

96 P. Poizot, S. Laruelle, S. Grugeon, L. Dupont and J.-M. Tarascon, Ionics, 2000, 6, 321-330.

97 V. Augustyn and B. Dunn, Electrochim. Acta, 2013, 88, 530535.

98 J. Livage, Nat. Mater., 2003, 2, 297-299.

99 J. Livage, Chem. Mater., 1991, 3, 578-593.

$100 \mathrm{~K}$. West, B. Zachau-Christiansen, T. Jacobsen and S. Skaarup, Electrochim. Acta, 1993, 38, 1215-1220.

101 J. H. Harreld, W. Dong and B. Dunn, Mater. Res. Bull., 1998, 33, 561-567.

102 V. Petkov, P. N. Trikalitis, E. S. Bozin, S. J. L. Billinge, T. Vogt and M. G. Kanatzidis, J. Am. Chem. Soc., 2002, 124, 10157-10162.

103 P. E. Tang, J. S. Sakamoto, E. Baudrin and B. Dunn, J. NonCryst. Solids, 2004, 350, 67-72.

104 G. G. Amatucci, F. Badway, A. Singhal, B. Beaudoin, G. Skandan, T. Bowmer, I. Plitz, N. Pereira, T. Chapman and R. Jaworski, J. Electrochem. Soc., 2001, 148, A940-A950.

105 J. Livage, Solid State Ionics, 1996, 86-88, 935-942.

106 Z. Chen, V. Augustyn, X. Jia, Q. Xiao, B. Dunn and Y. Lu, ACS Nano, 2012, 6, 4319-4327.

107 S. Boukhalfa, K. Evanoff and G. Yushin, Energy Environ. Sci., 2012, 5, 6872-6879.

108 I.-H. Kim, J.-H. Kim, B.-W. Cho and K.-B. Kim, J. Electrochem. Soc., 2006, 153, A1451-A1458.
109 Y. S. Cohen and D. Aurbach, Electrochem. Commun., 2004, 6, 536-542.

110 M. Tournoux, R. Marchand and L. Brohan, Prog. Solid State Chem., 1986, 17, 33-52.

111 M. Zukalová, M. Kalbáč, L. Kavan, I. Exnar and M. Graetzel, Chem. Mater., 2005, 17, 1248-1255.

112 E. Morgado, P. M. Jardim, B. A. Marinkovic, F. C. Rizzo, M. A. S. de Abreu, J. L. Zotin and A. S. Araújo, Nanotechnology, 2007, 18, 495710.

113 J. Li, Z. Tang and Z. Zhang, Chem. Mater., 2005, 17, 58485855.

114 J. Li, Z. Tang and Z. Zhang, Electrochem. Commun., 2005, 7, 62-67.

115 M. Wei, K. Wei, M. Ichihara and H. Zhou, Electrochem. Commun., 2008, 10, 1164-1167.

116 G.-N. Zhu, C.-X. Wang and Y.-Y. Xia, J. Power Sources, 2011, 196, 2848-2853.

117 Y. Wang, Z. Hong, M. Wei and Y. Xia, Adv. Funct. Mater., 2012, 22, 5185-5193.

118 A. G. Dylla, G. Henkelman and K. J. Stevenson, Acc. Chem. Res., 2013, 46, 1104-1112.

119 A. G. Dylla, P. Xiao, G. Henkelman and K. J. Stevenson, J. Phys. Chem. Lett., 2012, 3, 2015-2019.

120 S. Liu, H. Jia, L. Han, J. Wang, P. Gao, D. Xu, J. Yang and S. Che, Adv. Mater., 2012, 24, 3201-3204.

121 B. Reichman and A. J. Bard, J. Electrochem. Soc., 1981, 128, 344-346.

122 B. Reichman and A. J. Bard, J. Electrochem. Soc., 1980, 241242.

123 J. W. Kim, V. Augustyn and B. Dunn, Adv. Energy Mater., 2012, 2, 141-148.

124 T. Ohzuku, K. Sawai and T. Hirai, J. Power Sources, 1987, 19, 287-299.

125 C.-P. Liu, F. Zhou and V. Ozolins, in American Physical Society Meeting, Boston, 2012, http://meetings.aps.org/ link/BAPS.2012.MAR.B26.3.

126 A. A. Lubimtsev, P. R. C. Kent, B. G. Sumpter and P. Ganesh, J. Mater. Chem. A, 2013, 1, 14951-14956.

127 Z. Chen, V. Augustyn, J. Wen, Y. Zhang, M. Shen, B. Dunn and Y. Lu, Adv. Mater., 2011, 23, 791-795.

128 A. R. Armstrong, G. Armstrong, J. Canales, R. Garcia and P. G. Bruce, Adv. Mater., 2005, 17, 862-865.

129 H. Bin Wu, X. W. Lou and H. H. Hng, Chem.-Eur. J., 2012, 18, 3132-3135.

130 J. S. Chen, H. Liu, S. Z. Qiao and X. W. Lou, J. Mater. Chem., 2011, 21, 5687-5692.

131 V. Augustyn, E. R. White, J. Ko, G. Grüner, B. C. Regan and B. Dunn, Mater. Horiz., 2014, 1, 219-223. 